\title{
Transplants of Fibroblasts Genetically Modified to Express BDNF Promote Regeneration of Adult Rat Rubrospinal Axons and Recovery of Forelimb Function
}

\author{
Yi Liu, ${ }^{1}$ Duckhyun Kim, ${ }^{1}$ B. Timothy Himes, ${ }^{1,2}$ Stella Y. Chow, ${ }^{1}$ Timothy Schallert, ${ }^{3}$ Marion Murray, ${ }^{1}$ \\ Alan Tessler, ${ }^{1,2}$ and Itzhak Fischer ${ }^{1}$ \\ ${ }^{1}$ Department of Neurobiology and Anatomy, Medical College of Pennsylvania/Hahnemann University, Philadelphia, \\ Pennsylvania 19129, ${ }^{2}$ Philadelphia Veterans Administration Hospital, Philadelphia, Pennsylvania 19104, and ${ }^{3}$ Department \\ of Psychology and Institute for Neuroscience, University of Texas at Austin, Austin, Texas 78712
}

Adult mammalian CNS neurons do not normally regenerate their severed axons. This failure has been attributed to scar tissue and inhibitory molecules at the injury site that block the regenerating axons, a lack of trophic support for the axotomized neurons, and intrinsic neuronal changes that follow axotomy, including cell atrophy and death. We studied whether transplants of fibroblasts genetically engineered to produce brain-derived neurotrophic factor (BDNF) would promote rubrospinal tract (RST) regeneration in adult rats. Primary fibroblasts were modified by retroviral-mediated transfer of a DNA construct encoding the human BDNF gene, an internal ribosomal entry site, and a fusion gene of lac $Z$ and neomycin resistance genes. The modified fibroblasts produce biologically active BDNF in vitro. These cells were grafted into a partial cervical hemisection cavity that completely interrupted one RST. One and two months after lesion and transplantation, RST regeneration was demonstrated with retrograde and anterograde trac- ing techniques. Retrograde tracing with fluorogold showed that $\sim 7 \%$ of RST neurons regenerated axons at least three to four segments caudal to the transplants. Anterograde tracing with biotinylated dextran amine revealed that the RST axons regenerated through and around the transplants, grew for long distances within white matter caudal to the transplant, and terminated in spinal cord gray matter regions that are the normal targets of RST axons. Transplants of unmodified primary fibroblasts or Gelfoam alone did not elicit regeneration. Behavioral tests demonstrated that recipients of BDNF-producing fibroblasts showed significant recovery of forelimb usage, which was abolished by a second lesion that transected the regenerated axons.

Key words: spinal cord injury; cell transplantation; retrovirus; axon regeneration; anterograde tracing; retrograde tracing; neurotrophin; recovery of function
Most of the functional deficits after spinal cord injury result from the interruption of descending and ascending axons and the lack of successful regeneration. The failure of axons to regenerate is now generally attributed to the nonpermissive environment of the adult mammalian CNS, the lack of trophic/tropic support for axotomized neurons, and changes intrinsic to the neurons after axotomy (Tetzlaff et al., 1994; Schwab and Bartholdi, 1996; Joosten, 1997; Tessler et al., 1997; Stichel and Muller, 1998).

The strategies that have been used to promote regeneration of injured mammalian CNS axons are designed, in general, to provide a growth-permissive environment or to enhance the regenerative effort of axotomized CNS neurons (for review, see Schwab and Bartholdi, 1996; Stichel and Muller, 1998). Examples of the first approach are to graft peripheral nerves (David and Aguayo, 1981; Richardson et al., 1982), fetal CNS tissue

\footnotetext{
Received Dec. 17, 1998; revised March 15, 1999; accepted March 22, 1999.

This work was supported by National Institutes of Health Grant NS24707 and Training Grants NS10090 and HD07467, the Eastern Paralyzed Veterans of America, the International Spinal Cord Research Trust, a Center of Excellence Grant from Medical College of Pennsylvania/Hahnemann University, and the Research Service of the Veterans Administration. We thank Dr. L. Lillien for the generous gift of the LIG retrovirus vectors, Dr. L. Reichardt for the human BDNF cDNA, and Dr. J. Solowska-Baird for constructing LIG/BDNF. We thank Maryla Obrocka, Theresa Connors, and Kathy Bozek for their technical help.

Correspondence should be addressed to Dr. Itzhak Fischer, Department of Neurobiology and Anatomy, Medical College of Pennsylvania/Hahnemann University, 3200 Henry Avenue, Philadelphia, PA 19129.

Copyright (C) 1999 Society for Neuroscience $0270-6474 / 99 / 194370-18 \$ 05.00 / 0$
}

(Bernstein-Goral and Bregman, 1993; Himes et al., 1994; Iwashita et al., 1994; Miya et al., 1997; Mori et al., 1997; Diener and Bregman, 1998), or non-neuronal cells (Xu et al., 1995a,b; Chen et al., 1996; Honmou et al., 1996; Li et al., 1997), or to neutralize CNS inhibitory molecules (Caroni and Schwab, 1988; Schnell and Schwab, 1990, 1993; Bregman et al., 1995; Z'Graggen et al., 1998) (for review, see Schwab and Bartholdi, 1996). In the second category, examples are application of neurotrophic factors (Diener and Bregman, 1994; Tetzlaff et al., 1994; Oudega and Hagg, 1996; Kobayashi et al., 1997; Shibayama et al., 1998) or overexpression of growth-associated genes (e.g., GAP-43, c-Jun, and Bcl-2). None of these strategies alone has been sufficient in the adult CNS, but in combination they have elicited regeneration from several descending pathways (Schnell et al., 1994; Xu et al., 1995a; Cheng et al., 1996; Bregman et al., 1997; Kobayashi et al., 1997; Ye and Houle, 1997).

Ex vivo gene therapy is an especially promising approach because the CNS environment can be modified, and neurotrophic factors can be delivered by one manipulation. In this strategy, cultured cells are genetically modified to express therapeutic gene products, such as neurotrophins, and then grafted into a CNS lesion site to deliver the therapeutic products and to reestablish tissue continuity (Gage et al., 1987; Whittemore and Snyder, 1996; Snyder and Senut, 1997). Genetically engineered fibroblasts have been shown to promote axon regeneration in brain (Rosenberg et al., 1988; Kawaja et al., 1992), and intraspinal grafts of 


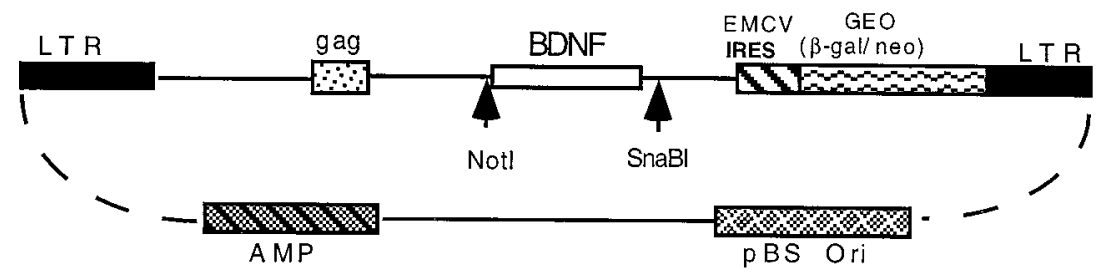

Figure 1. The LIG/BDNF retrovirus. The virus encodes the full-length human BDNF cDNA and GEO, which is a fusion gene of $\beta$-gal and neomycin resistance genes. The entire BDNF-IRES-GEO sequence is driven by the RSV LTR promoter and is transcribed into a polycistron mRNA. The EMCV IRES located between BDNF and GEO allows cap-independent initiation of translation of the polycistron mRNA. neurotrophin-3 (NT-3)-expressing fibroblasts have enhanced corticospinal tract (CST) regeneration (Grill et al., 1997). However, the regenerating CST axons failed to grow into the graft or host white matter, and the length of growth was very limited (Grill et al., 1997). NT-3 and brain-derived neurotrophic factor (BDNF)producing fibroblasts have also been shown to induce oligodendrocyte proliferation and axon remyelination after spinal cord contusion (McTigue et al., 1998).

In the present study, we have used a gene therapy strategy to elicit regeneration of the rubrospinal tract (RST). The rubrospinal system is readily identified by retrograde or anterograde tracers, and rubrospinal neurons are known to express the fulllength Trk-B receptor, which accounts for a regenerative response to the application of the neurotrophins BDNF and NT-4/5 (Xu et al., 1995a; Kobayashi et al., 1997; Ye and Houle, 1997). In addition, the almost complete $(>99 \%)$ contralateral trajectory of RST allows an unambiguous interpretation of the anatomical tracing results (Brown, 1974), in contrast to other descending pathways in which spared axons and collateral sprouting may complicate the interpretation (Waldron and Gwyn, 1969; Tracey, 1995).

We tested regeneration in a partial cervical hemisection model in which the lateral funiculus (containing the entire RST) and part of the ventral white matter were ablated, whereas the ipsilateral gray matter was partially preserved and the dorsal columns and CST were left intact (see Fig. 2). This model resembles the lesion paradigms in which RST regeneration into a peripheral nerve graft has been observed previously (Richardson et al., 1984; Kobayashi et al., 1997) but preserves the host gray matter, which is a potential growth substrate for regenerating axons (Cheng et al., 1996; Grill et al., 1997). We demonstrate that intraspinal grafts of primary fibroblasts genetically engineered to express BDNF promote RST regeneration and functional recovery in adult rats with high cervical spinal cord injury.

\section{MATERIALS AND METHODS}

Preparation of the retrovirus vector, the packaging cell line, and BDNFproducing fibroblasts. A retroviral construct (Fig. 1) encoding the BDNF.IRES.GEO sequence was prepared using the LIG vector (provided by Dr. L. Lillien, University of Pittsburgh) and a 850 bp fragment of the human BDNF cDNA containing the coding region (provided by Dr. L. Reichardt, University of California at San Francisco). The BDNF fragment was isolated by digestion with NotI-EcoRV restriction enzymes and subcloned into the NotI-SnaBI sites of LIG as shown in Figure 1. The resulting vector, which was named LIG/BDNF, contained the human BDNF gene, an encephalomyocarditis virus (EMCV) internal ribosomal entry site (IRES), and a GEO gene that is a fusion gene of the lacZ (encoding Escherichia coli $\beta$-galactosidase) and neomycin resistance (neo) genes. The entire BDNF.IRES.GEO sequence is driven by the Rous sarcoma virus (RSV) long terminal repeat (LTR) and is transcribed as a multicistronic mRNA. The IRES directs cap-independent translation of the mRNA by providing internal binding sites for ribosomes and ensures efficient coexpression of the BDNF and GEO genes (Jang and Wimmer, 1990; Ghattas et al., 1991; Kim et al., 1992; Morgan et al., 1992). The vector was used to transfect the packaging cell line $\psi^{2}$ (Mann et al., 1983; Miller, 1990), and neomycin resistant clones were selected in the presence of $600 \mu \mathrm{g} / \mathrm{ml}$ G418 (Life Technologies, Grand Island, NY). A clone $\left(\psi^{2}\right.$-BDNF) that produced the highest viral titer was propagated and stored. Frozen aliquots of virus were gradually thawed on ice, mixed with $8 \mu \mathrm{g} / \mathrm{ml}$ polybrene, and applied onto rapidly dividing rat primary fibroblasts isolated from abdominal skin. Fresh growth medium was replenished after $4 \mathrm{hr}$, and the transduced cells were selected with G418. Transgene expression by the engineered fibroblasts was monitored by X-gal histological staining for $\beta$-galactosidase (Liu et al., 1997a). Clones containing high percentages $(>90 \%)$ of X-gal-positive cells were propagated, stored, and used in transplantation experiments. Several methods, including Western blotting (Liu et al., 1997b), slot blot, immunocytochemistry, and bioassay with embryonic day 8 (E8) chicken DRG explant (Horie et al., 1991), were used to verify the production of biologically active BDNF (see below).

Cell culture. Primary fibroblasts (Fb) and BDNF-expressing fibroblasts $(\mathrm{Fb} / \mathrm{BDNF}$ ) were cultured as described previously (Liu et al., 1998). For surgery or stock, the cells were grown on $100 \mathrm{~mm}$ uncoated tissue culture dishes (Becton Dickinson Labware, Franklin Lakes, NJ) and split weekly at 1:10 ratio into fresh medium. Twenty-four hours before surgery, cells were labeled with the nuclear dye bisBenzimide (Sigma Aldrich Co., Irvine, England) as described (Menei et al., 1998). On the day of surgery, confluent cultures of cells were washed with HBSS (Life Technologies), trypsinized, gently triturated, counted, washed, pelleted (900 rpm for 5 min), and resuspended in growth medium at a concentration of $10^{5}$ cells $/ \mu$ l. The cells were maintained on ice during surgery. After each surgery, some of the remaining cells were stained with Trypan Blue (Sigma Aldrich), and the rest were replated and stained by X-gal histochemistry to verify viability and transgene expression. For in vitro histochemical and immunocytochemical staining, $\mathrm{Fb}$ and $\mathrm{Fb} / \mathrm{BDNF}$ were seeded into adjacent chambers of eight-chamber LabTek glass slides (Nalge Nunc, Naperville, IL), cultured for 3-4 d, and fixed with $4 \%$ paraformaldehyde or $0.5 \%$ glutaraldehyde (Electron Microscopy Sciences, Ft. Washington, PA). Unless specified, culture supplies were purchased from Fisher Scientific (Pittsburgh, PA).

Western blot and slot blot analysis. To verify BDNF expression, immunoblotting with polyclonal anti-human-BDNF antibody (see Table 2) was performed according to the procedure described previously (Liu et al., 1997b). Briefly, the day before harvest, cells grown on 24-well plates (Becton Dickinson) were washed with HBSS, fed with $500 \mu$ l serum-free DMEM, and cultured for another $24 \mathrm{hr}$. The conditioned medium was collected and mixed with an equal volume of $2 \times$ sample buffer containing $125 \mathrm{~mm}$ Tris, $4 \%$ SDS, $20 \%$ glycerol, and 10\% 2-mercaptoethanol, $\mathrm{pH}$ 6.8. The cell layer was gently scraped off and homogenized with a Teflon-glass homogenizer in $5 \mathrm{vol}$ of homogenization buffer $(50 \mathrm{~mm}$ Tris, pH 7.5, 2 mM EDTA, 1 mM PMSF, 25 mm leupeptin, 1.0\% aprotinin). The homogenate was centrifuged at $15,000 \times g$ for $10 \mathrm{~min}$ at $4^{\circ} \mathrm{C}$. The supernatant was then mixed with an equal amount of $2 \times$ sample buffer. Samples containing media or cell homogenates were loaded onto adjacent lanes and separated by $15 \%$ SDS-PAGE, then transferred onto nitrocellulose (NC) membranes, and processed for Western blotting. The NC membranes were blocked with $5 \%$ nonfat dry milk in TTBS buffer $(0.1 \%$ Tween $20,150 \mathrm{~mm} \mathrm{NaCl}, 50 \mathrm{~mm}$ Tris-HCl, $\mathrm{pH}$ 7.6) and incubated overnight with primary antibodies for BDNF (1:50 dilution). After three rinses with TTBS buffer, the membranes were incubated with HRPconjugated secondary antibody (Jackson ImmunoResearch Laboratories, West Grove, PA; diluted 1:4000) for $1 \mathrm{hr}$. The immunoreactivity was visualized by chemiluminescence with ECL reagents (Amersham, Arlington Heights, IL). Recombinant human-BDNF (Regeneron Pharmaceutical, Tarrytown, NY) and cells that had not been genetically modified were used in the analysis as controls for the specificity of the antibody. For slot blot analysis, recombinant human BDNF and supernatant samples $(100 \mu \mathrm{l})$ from $\mathrm{Fb}$ or $\mathrm{Fb} / \mathrm{BDNF}$ were applied onto $\mathrm{NC}$ membrane with a slot blot apparatus, dried overnight, and processed for immunostaining with the BDNF antibody.

$B D N F$ bioassay. Conditioned media from $\mathrm{Fb}$ or $\mathrm{Fb} / \mathrm{BDNF}$ were tested for the production of bioactive BDNF using an E8 chicken DRG explant bioassay that has been described before (Horie et al., 1991). Briefly, confluent cultures of cells were split onto $50 \mathrm{~mm}$ culture dishes at 1:3 


\begin{tabular}{|c|c|c|c|c|}
\hline \multirow[b]{2}{*}{ Animal groups } & \multicolumn{2}{|c|}{1 month $(n)$} & \multicolumn{2}{|c|}{2 months $(n)$} \\
\hline & FG & BDA & FG & $\mathrm{BDA}$ \\
\hline \multicolumn{5}{|c|}{ Experimental group I-tracing analysis (total $n=72$ ) } \\
\hline $\mathrm{Hx}+\mathrm{FB} / \mathrm{BDNF}$ & 6 & 6 & 6 & 6 \\
\hline $\mathrm{Hx}+\mathrm{FB}$ & 6 & 6 & 6 & 6 \\
\hline $\mathrm{Hx}+\mathrm{GF}$ & 6 & 6 & 6 & 6 \\
\hline \multicolumn{5}{|c|}{ Experimental group II-behavioral analysis (total $n=18$ ) } \\
\hline $\mathrm{Hx}+\mathrm{FB} / \mathrm{BDNF}$ & & & 6 & \\
\hline $\mathrm{Hx}+\mathrm{FB}$ & & & 6 & \\
\hline $\mathrm{Hx}+\mathrm{GF}$ & & & 5 & \\
\hline \multicolumn{5}{|c|}{ Tracing control groups (total $n=9$ ) } \\
\hline Normal+FG & & & 3 & \\
\hline Normal+BDA & & & 6 & \\
\hline
\end{tabular}

$\overline{\text { FG, Fluorogold retrograde tracing; BDA, biotinalyted dextran amine anterograde }}$ tracing; $\mathrm{Hx}+\mathrm{FB} / \mathrm{BDNF}$, hemisection and BDNF-producing fibroblast transplant; $\mathrm{Hx}+\mathrm{FB}$, hemisection and unengineered fibroblast transplant; and $\mathrm{Hx}+\mathrm{GF}$, hemisection and Gelfoam transplant.

ratio (Becton Dickinson). The cells were then cultured for $24 \mathrm{hr}$. On the second day, after three rinses with HBSS, low serum (0.1\% FCS) medium was used to feed the cells. The cells were then cultured for another $24 \mathrm{hr}$, and conditioned media were collected for bioassay. Fertile eggs were purchased from SPAFAS (Preston, CT). The eggs were incubated in a humidified incubator at $37^{\circ} \mathrm{C}$ for $8 \mathrm{~d}$ before use. Eggs containing E8 embryos were opened, and the embryos were removed to a sterile Petri dish containing prewarmed $\left(37^{\circ} \mathrm{C}\right)$ DMEM with $0.1 \%$ heat-inactivated goat serum. Meninges and connective tissue were removed, and lumbar DRG were gently dissected out and embedded in a 12-well culture plate containing $600 \mu \mathrm{l}$ of collagen gel that was prepared by mixing solutions A $\left(\mathrm{CH}_{3} \mathrm{COOH}\right.$ containing $0.3 \%$ rat tail type I collagen; Upstate Biotechnology, Lake Placid, NY), B (10× DMEM), and C (2.2 gm $\mathrm{NaHCO}_{3}$, $4.77 \mathrm{gm}$ HEPES in $100 \mathrm{ml} 0.05 \mathrm{~N} \mathrm{NaOH}$ ) at a ratio of 4:1:1. Three DRGs were placed into each well of the 12 -well plate, and the gel solution was allowed to solidify by incubation at $37^{\circ} \mathrm{C}$ for $20 \mathrm{~min}$. Conditioned medium $(400 \mu \mathrm{l})$ from $\mathrm{Fb}, \mathrm{Fb} / \mathrm{BDNF}$, or culture medium alone was then applied onto wells containing the DRG explants. The conditioned media were used without dilution or diluted at 1:2 and 1:10. Neurite outgrowth from the DRG was examined at $24-48 \mathrm{hr}$ and compared with 15,45 , and $450 \mathrm{ng} / \mathrm{ml}$ recombinant human-BDNF.

Immunosuppression with cyclosporin A. Cyclosporin A (CsA) injection solution (Sandoz Pharmaceuticals, East Hanover, NJ) was administered subcutaneously at a dose of $1 \mathrm{mg} / 100 \mathrm{gm}$ body weight. The daily CsA injection started 3-5 d before the transplantation procedures and continued for 2 weeks after operation. After this, oral CsA solution (Sandoz, East Hanover, NJ) was administered via the drinking water $(50 \mu \mathrm{g} / \mathrm{ml})$ and continued throughout the survival period.

Animal groups. A total of 105 female Sprague Dawley rats (250-300 gm; Taconic, Germantown, NY) were studied. All procedures were approved by the institutional animal welfare committee and were in accord with the National Institutes of Health guidelines for the care and use of laboratory animals. Animals were divided into three groups (Table 1). Rats in experimental group I $(n=72)$ (Table 1, Fig. 2$)$ received a partial hemisection of the right side of the spinal cord and a transplant of $\mathrm{Fb} / \mathrm{BDNF}, \mathrm{Fb}$, or Gelfoam alone ( $n=24$, for each transplant group). The RST of these rats was then traced retrogradely by fluorogold (FG, $n=36$ ) or anterogradely by biotinylated dextran amine (BDA, $n=36$ ). These animals were examined at 1 or 2 months $(n=36$ for each time point). Rats in experimental group II (Table 1) received the identical spinal cord lesion as experimental group I and a transplant of $\mathrm{Fb} / \mathrm{BDNF}$, $\mathrm{Fb}$, or Gelfoam alone ( $n=6$ for each group). They were tested weekly for 2 months for recovery of control of forelimb movement. They then received a second lesion at $\mathrm{C} 2$ to section the right dorsolateral quadrant and were tested weekly for another 2 months before they were killed and anatomical analysis was performed. These animals did not receive FG or BDA injection, because the tracing procedures introduce additional CNS lesions that may interfere with the interpretation of behavioral results. Animals in the tracing control group (Table 1) received FG $(n=3)$ or BDA injections $(n=6)$. An additional group of six animals received
$\mathbf{A}$

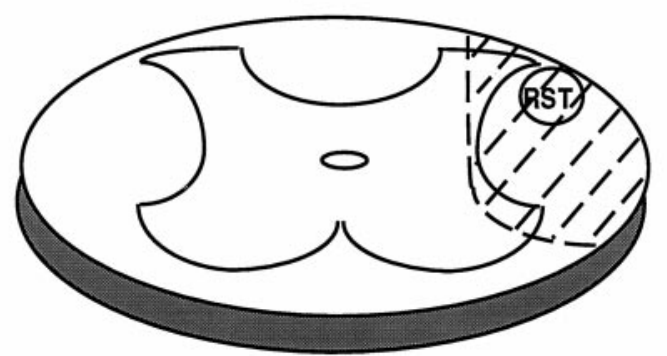

B

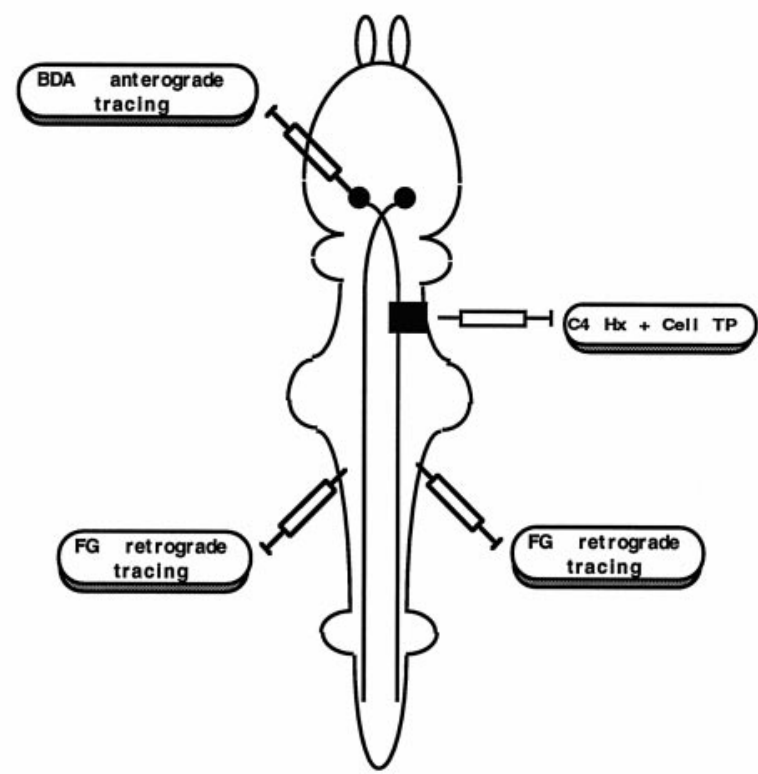

Figure 2. Schematic diagram of the experimental paradigm. Animals received a right $\mathrm{C} 3-4$ partial hemisection that disrupted the axons from the left RN. $A$, Drawing of a spinal cord cross section; the lesion and transplant are represented by the shaded area. Immediately after the spinal cord lesion, Gelfoam, $\mathrm{Fb}$, or $\mathrm{Fb} / \mathrm{BDNF}$ cells were grafted into the lesion cavity. RST regeneration was studied using either BDA anterograde tracing or FG retrograde tracing $(B)$.

spinal cord lesions and $\mathrm{Fb} / \mathrm{BDNF}$ transplants and were killed at 1 week to evaluate transgene expression.

Surgical procedures. Rats were anesthetized with an intraperitoneal injection of acepromazine maleate $(0.7 \mathrm{mg} / \mathrm{kg}$; Fermenta Animal Health Co., Kansas City, MO), ketamine $(95 \mathrm{mg} / \mathrm{kg}$, Fort Dodge Animal Health, Fort Dodge, IA), and xylazine $(10 \mathrm{mg} / \mathrm{kg}$, Bayer Co., Shawnee Mission, KS), and underwent laminectomy at the C3-4 level to expose one spinal cord segment. After hemostasis was achieved, the spinal cord midline and the dorsal root entry zone were identified. A microscalpel was used to open the dura and pia mater and to make a shallow incision in the right dorsal spinal cord. A fine-tipped glass-pulled microaspiration device was then used to extend the lesion laterally and ventrally (Fig. 2). Such a lesion completely disrupted the lateral funiculus (containing the RST) and partially lesioned the ipsilateral ventral funiculus and gray matter but left the dorsal columns intact (Fig. 2A). The rostrocaudal extent of the lesion cavity was $\sim 2-3 \mathrm{~mm}$. A piece of Gelfoam soaked with $\mathrm{Fb} / \mathrm{BDNF}, \mathrm{Fb}$ cells, or growth medium alone was implanted into the cavity, and then another $10 \mu \mathrm{l}$ of cells suspended in growth medium were slowly injected onto the Gelfoam with a $10 \mu \mathrm{l}$ Hamilton syringe attached to a glass pipette (tip diameter $50 \mu \mathrm{m}$ ). The dura was closed with interrupted $10-\varnothing$ silk sutures, and the muscle and skin were closed in layers. Immediately after the completion of the procedure (within $10 \mathrm{~min}$ of the spinal cord lesion), all rats received a bolus intravenous injection of methylprednisolone $(30 \mathrm{mg} / \mathrm{kg}$; Pharmacia and Upjohn Company, 
Table 2. Primary antibodies

\begin{tabular}{|c|c|c|c|}
\hline & Type & Dilution & Sources \\
\hline Anti-human BDNF & chicken pAb IgY & $1: 100$ & Promega (Madison, WI) \\
\hline Anti- $\beta$-gal & $\mathrm{pAb}$ IgG & $1: 1000$ & $5^{\prime} \rightarrow 3^{\prime}$ Inc. (Boulder, CO) \\
\hline RT-97 & mAb IgG1 & $1: 100$ & $\begin{array}{l}\text { Boehringer Mannheim } \\
\text { (GmbH, Germany) }\end{array}$ \\
\hline Anti-5-HT & $\mathrm{pAb}$ IgG & $1: 10,000$ & Eugene Tech. (Ridgefield, NJ) \\
\hline Anti-CGRP & $\mathrm{pAb}$ IgG & $1: 10,000$ & $\begin{array}{l}\text { Peninsula Laboratories (Bel- } \\
\text { mont, CA) }\end{array}$ \\
\hline Anti-D $\beta \mathrm{H}$ & $\mathrm{pAb}$ IgG & $1: 5000$ & Eugene Tech. \\
\hline Anti-ChaT & $\mathrm{pAb}$ IgG & $1: 500$ & Incstar (Stillwater, MN) \\
\hline Anti-GFAP & $\mathrm{pAb}$ IgG & $1: 500$ & $\begin{array}{l}\text { Biomedical Technologies } \\
\text { (Stoughton, MA) }\end{array}$ \\
\hline $\mathrm{OX}-42$ & $\mathrm{mAb}$ IgG & $1: 500$ & $\begin{array}{l}\text { Harlan Bioproducts for Science } \\
\text { (Indianapolis, IN) }\end{array}$ \\
\hline ED-1 & $\mathrm{mAb} \mathrm{IgG}$ & $1: 500$ & Harlan Bioproducts for Science \\
\hline
\end{tabular}

Kalamazoo, MI) through the tail vein. After the surgery, animals were kept on heating pads, closely observed until awake, and then returned to their home cages. For re-lesion experiments, animals in experimental group II (Table 1) were anesthetized and subjected to a second laminectomy at $\mathrm{C} 2$, followed by removal of the right dorsolateral quadrant using the same procedure as described above. For retrograde tracing with FG, $3 \mathrm{~d}$ before they were killed, anesthetized animals received another laminectomy 3-4 segments caudal to the initial lesion-transplant site; $1 \mu \mathrm{l}$ $2 \%$ FG (Fluorochrome, Englewood, $\mathrm{CO}$ ) was pressure-injected into each side of the spinal cord, and animals were killed $3 \mathrm{~d}$ later. For BDA anterograde tracing, $15 \mathrm{~d}$ before kill, the animals were anesthetized and positioned on a stereotaxic apparatus, and a dental drill was used to make a burr hole according to the coordinates described previously (Mori et al., 1997). One microliter of 10\% BDA (Molecular Probes, Eugene, OR) was slowly injected over $2-3 \mathrm{~min}$ as five $200 \mathrm{nl}$ pulses using a $10 \mu \mathrm{l}$ Hamilton syringe. The needle was left in place for another $20 \mathrm{~min}$ and gradually withdrawn over 2-3 min.

Tissue preparation. Before they were killed, animals were anesthetized with an intraperitoneal injection of sodium pentobarbital $(100 \mathrm{mg} / \mathrm{kg}$; Abbott Laboratories, North Chicago, IL) and perfused through the heart with $200 \mathrm{ml}$ of physiological saline (FG animals) or normal saline (BDA animals) followed by $500 \mathrm{ml}$ of ice-cold $4 \%$ paraformaldehyde in $0.1 \mathrm{M}$ phosphate buffer, $\mathrm{pH}$ 7.4. The entire brain and spinal cord were dissected out and immersed in $0.1 \mathrm{M}$ phosphate buffer (PB) at $4^{\circ} \mathrm{C}$ overnight followed by cryoprotection in $30 \%$ sucrose (in $0.1 \mathrm{M} \mathrm{PB}$ containing 0.5 mM Thimerosal) for 3-5 d. Spinal cord and brain tissue were serially blocked, embedded in OCT compound (Fisher Scientific, Pittsburgh, PA), and kept at $-80^{\circ} \mathrm{C}$ before being cut into $20 \mu \mathrm{m}$ (spinal cord) or 40 $\mu \mathrm{m}$ (brain) sections on a cryostat and mounted onto gelatin-coated slides.

Histology and immunocytochemistry. X-gal histochemical and immunocytochemical staining procedures were described before (Liu et al., 1997a). Briefly, for immunocytochemistry (ICC) staining of cultured cells, $\mathrm{Fb} / \mathrm{BDNF}$ or Fb cells seeded in adjacent chambers on Lab-Tek slides were stained with an anti-BDNF antibody and/or an anti- $\beta$-gal antibody to check for transgene expression. The experiments were repeated at least three times. For ICC staining of spinal cord tissue, $20 \mu \mathrm{m}$ sections were stained with primary antibodies listed in Table 2. The reactions were performed either with an $\mathrm{ABC}$ kit (Vector Labs, Burlingame, CA) or with fluorescent secondary antibodies. The fluorescent secondary antibodies, including FITC-conjugate donkey anti-rabbit $\operatorname{IgG}(\mathrm{H}+\mathrm{L})$, Texas Red-conjugate donkey anti-rabbit $\operatorname{IgG}(\mathrm{H}+\mathrm{L})$, FITCconjugate goat anti-mouse IgG $+\mathrm{IgM}$, and Texas Red-conjugate goat anti-mouse $\operatorname{IgG}(\mathrm{H}+\mathrm{L})$ (diluted 1:100) were purchased from Jackson ImmunoResearch. The specificity of the immunostaining was verified in sister cultures or adjacent sections by omitting primary or secondary antibodies.

Detection of BDA-labeled fibers. BDA-labeled fibers were detected either by staining with an $\mathrm{ABC}$ elite kit (Vector) and visualized with $\mathrm{DAB}$ as a chromagen or with FITC-avidin (Vector). These procedures were modified from the protocols described by Brosamle and Schwab (1997). For the ABC elite reaction, slides were rinsed three times, $30 \mathrm{~min}$ each, in TBST (50 mm Tris-buffered saline containing $0.5 \%$ Triton $\mathrm{X}-100, \mathrm{pH} 10.0$ ), then incubated overnight with an avidin-biotin-peroxidase complex at room temperature. On the second day, after three 30 min rinses in TBST and a short rinse in $50 \mathrm{~mm}$ Tris buffer, the sections were reacted with Sigma Fast-DAB compounds according to the manufacturer's instructions (Sigma, St. Louis, MO), dehydrated, and coverslipped with DPX (Fluka Chemie AG, Buchs, Switzerland). For FITCavidin reaction, sections were rinsed three times for $30 \mathrm{~min}$ with TBST, incubated overnight with FITC-avidin (1:200 dilution), rinsed three times for 30 min with TBST, and coverslipped with Vectashield (Vector).

Behavioral testing. All rats were examined for forelimb use during spontaneous vertical exploration, a test that is highly sensitive to chronic limb use asymmetries (Schallert and Lindner, 1990; Schallert and Jones, 1993; Jones and Schallert, 1994; McDermott et al., 1995; Kozlowski et al., 1996; Choi-Lundberg et al., 1998). Repeated testing does not influence the asymmetry score, because weight-shifting movements initiated by the forelimbs are typically used by the animal in its home cage.

The rats were placed in a clear Plexiglas cylinder $(20 \mathrm{~cm}$ in diameter and $30 \mathrm{~cm}$ high) for $5 \mathrm{~min}$. The cylinder encourages use of the forelimbs for vertical exploration. A mirror was placed at an angle behind the cylinder so that the forelimbs could be viewed at all times. The testing session was videotaped, and forelimb usage was scored blindly at a later date.

The following behaviors were scored: (1) independent use of the left or right forelimb for contacting the wall of the cylinder during a full rear, to initiate a weight-shifting movement, or to regain center of gravity while moving laterally in a vertical posture along the wall; and (2) simultaneous or near-simultaneous use of both the left and right forelimb to contact the wall of the cylinder during a full rear and for lateral movements along the wall.

Each behavior was expressed in terms of (1) percentage use of the contralateral (nonimpaired) forelimb relative to the total number of ipsilateral, contralateral, and simultaneous (both) limb use observations; (2) percentage use of the ipsilateral (impaired) forelimb relative to the total number of ipsilateral, contralateral, and simultaneous (both) limb use observations; and (3) percentage simultaneous (both) limb use relative to the total number of ipsilateral, contralateral, or simultaneous (both) limb use observations.

During a rear, the first limb to contact the wall with clear weight support (without the other limb contacting the wall within $0.5 \mathrm{sec}$ ) was scored as an independent wall placement for that limb. After the first limb contacted the wall, a delayed placement of the other limb on the wall while the first limb remained anchored on the wall was counted as an additional movement and scored as simultaneous (both). For example, if an animal placed its contralateral limb on the wall, followed by delayed contact with both forelimbs, the animal would receive a score of one "contralateral" and one "both" for that sequence. If only one forelimb contacted the wall, all lateral movements thereafter were each scored as independent movements of that limb until the other forelimb contacted the wall with weight support, at which point one "both" was scored. If the rat continued to explore the wall laterally in a rearing posture while alternating both limbs on the wall, a "both" was recorded, and every 
additional combination of two-limb movements (wall stepping) received a "both" score. Thus, both paws must be removed from the vertical surface before another movement can be scored. If the animal removed both forelimbs from the wall during a rear and then immediately resumed wall exploration, the movements were again scored as independent (left or right) or simultaneous (both) as described above.

Baseline behavior was measured before surgery, and all the animals were tested weekly for 13 weeks after surgery. Two-way ANOVA (treatment $\times$ preferred limb) was performed to test for differences between animal groups, and one-way ANOVA was used to test for differences within a treatment group.

Image analysis and statistics. Images were captured using a Photometric Sensys KAF-1400 CCD camera (Photometric, Tucson, AZ) and a DC330 CCD color video camera (DAGE-MTI, Michigan City, IN) attached to a Leica DMRBE microscope (Wetzlar, Germany) and processed on a Macintosh Power PC 8500 with NIH image, IP Lab (Scanalytics, Fairfax, VA), and Photoshop (Adobe System Inc., San Jose, CA) image analysis software packages. In experimental group I animals (Table 1), because the FG-labeled cells were sparse in the injured red nucleus (RN), to avoid underestimating the number of regenerated RN cells, the FGlabeled neurons were counted in every section throughout the rostrocaudal extent of the RN, spanning $1000 \mu \mathrm{m}$ from the caudal pole (Kobayashi et al., 1997; Diener and Bregman, 1998). However, in tracing control animals and on the intact side of experimental animals, because RN was packed with brightly labeled neurons, to avoid overestimating, neurons were counted in every other section, and the number was multiplied by 2 to calculate the total number of neurons in each RN. Only those cells with identifiable nuclei, nucleoli, and characteristic neuronal morphology were counted. Adjacent sections were always compared with each other to avoid repeated counting. Images containing FG-labeled cells were captured at $100 \times$ magnification, and the cross-sectional area of the neurons was measured using NIH image software. All statistical analyses were performed using Microsoft Excel software (Microsoft, Redmond, WA).

\section{RESULTS}

\section{In vitro transgene expression by the genetically engineered fibroblasts}

The retroviral vector $\mathrm{LIG} / \mathrm{BDNF}$ (Fig. 1) encodes three genes that were essential for this experiment. BDNF was the gene of interest; $\beta$-gal/neo was a fusion gene composed of two reporter genes ( $\beta$-galactosidase and neomycin resistance). The neo gene enabled selection of the transfected producer cells and establishment of the packaging cell line $\psi^{2}$-BDNF. The $\beta$-gal gene allowed monitoring of in vitro and in vivo transgene expression and identification of the donor cells using a highly specific histological staining procedure (X-gal histochemistry). This vector design included the IRES sequence that linked the BDNF gene with the two reporter genes (Fig. 1). It has been shown that IRES directs cap-independent translation of the mRNA by providing internal binding sites for ribosomes (Jang and Wimmer, 1990; Ghattas et al., 1991; Kim et al., 1992; Morgan et al., 1992). The BDNF gene and the two reporter genes were therefore driven by a single LTR promoter. This design avoided the problem of independent gene expression associated with vectors that use multiple promoters to drive multiple gene expression (Ghattas et al., 1991). Because the IRES sequence ensures efficient (85-90\%) coexpression (Ghattas et al., 1991; our unpublished data), the reliable coexpression of the gene of interest (BDNF) and a reporter gene $(\beta$-gal) offered us a convenient way to monitor transgene expression both in vitro and in vivo. As shown in Figure $3 A-E$, BDNF antibody specifically stains nearly all of the $\mathrm{Fb} / \mathrm{BDNF}$ cells (Fig. $3 A$ ) but none of the unmodified primary fibroblasts (Fig. $3 B$ ). The same BDNF antibody has been used by other investigators to demonstrate in vitro BDNF expression by genetically engineered Schwann cells (Menei et al., 1998). When double-stained with BDNF and $\beta$-gal antibodies, virtually all cells in the culture were BDNF positive, as shown in Figure $3 C$ (see also Fig. $3 A$ ); $\sim 80-90 \%$ of cells were $\beta$-gal positive (Fig. $3 D$ ), and virtually all $\beta$-gal positive cells were

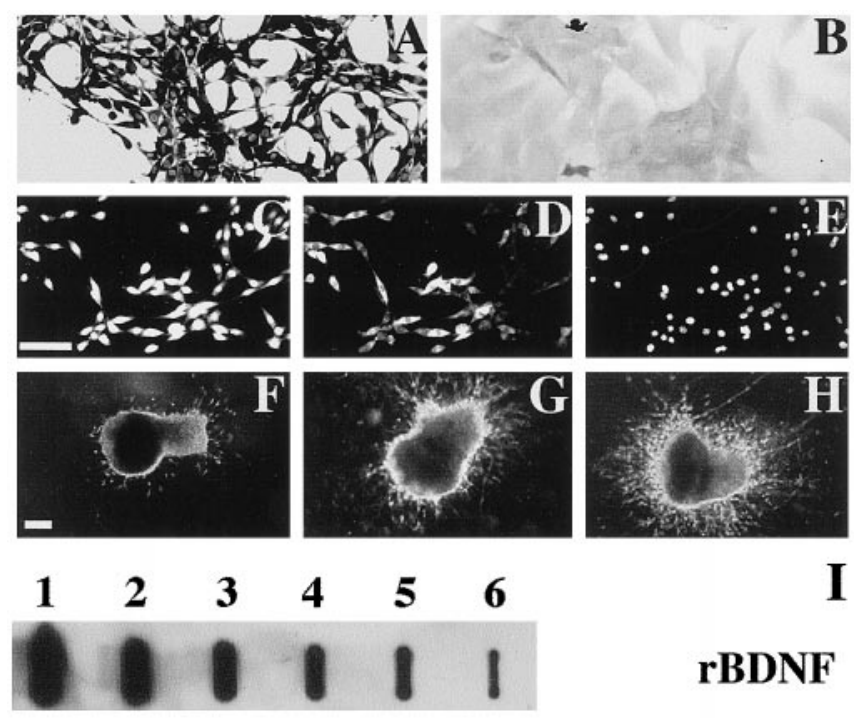

\section{Unmodified Fb}

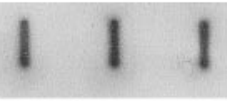

\section{$\mathbf{F b} / \mathbf{B D N F}$}

Figure 3. Analysis of in vitro transgene expression. Cultured $\mathrm{Fb} / \mathrm{BDNF}$ $(A, C-E)$ or $\mathrm{Fb}(B)$ cells were stained with an anti-BDNF antibody $(A, B)$ or double-labeled with anti-BDNF $(C)$ and anti- $\beta$-gal antibody $(D) . E$, From the same visual field as $C$ and $D$; cells are labeled with a nuclear dye (4',6-diamidino-2-phenylindole) to reveal the entire cell population in the culture. Conditioned media from $\mathrm{Fb}(F)$ or $\mathrm{Fb} / \mathrm{BDNF}(G)$ cells were analyzed for production of biologically active BDNF using an E8 chicken DRG explant assay. Recombinant human BDNF was used as a positive control $(H)$. The rate that $\mathrm{Fb} / \mathrm{BDNF}$ cells secrete $\mathrm{BDNF}$ was calculated relative to control recombinant $\mathrm{BDNF}$ using a slot blot assay $(I)$. Recombinant BDNF ( $r B D N F)$ was loaded onto a slot blot apparatus at 2000, $400,80,16,3.2$, and $0.064 \mathrm{ng}$ (lanes $1-6$, respectively) and compared with $20 \mu \mathrm{l}$ conditioned media from $\mathrm{Fb}$ and $\mathrm{Fb} / \mathrm{BDNF}$ (5000 cells in triplicates). $\mathrm{Fb} / \mathrm{BDNF}$ cells secrete BDNF at a rate of $12.8 \mathrm{ng} / 10^{6}$ cells per $24 \mathrm{hr}$, whereas $\mathrm{Fb}$ cells do not secrete detectable levels of BDNF. Scale bars, $100 \mu \mathrm{m}$.

BDNF positive, but some BDNF positive cells were not $\beta$-gal positive (Fig. $3 C, D$ ). On the basis of the in vitro immunocytochemical staining, we concluded that the Fb/BDNF cells expressed both BDNF and $\beta$-gal transgenes and that the IRES sequence therefore ensured high levels of coexpression of BDNF and $\beta$-gal, with a preference for BDNF. This result justified the use of $\mathrm{X}$-gal histochemistry to monitor in vivo transgene expression.

To verify that $\mathrm{Fb} / \mathrm{BDNF}$ cells secreted $\mathrm{BDNF}$, we tested homogenates of $\mathrm{Fb} / \mathrm{BDNF}$ or Fb cells and media conditioned by them using Western blot analysis. Anti-BDNF antibody detected a protein band in conditioned medium from $\mathrm{Fb} / \mathrm{BDNF}$ cells but not from unmodified cells. This protein had the same apparent molecular weight on a SDS-PAGE gel as commercially available recombinant human-BDNF. As expected, anti-BDNF antibody also detected the same band in homogenates of $\mathrm{Fb} / \mathrm{BDNF}$ but not $\mathrm{Fb}$ cells (data not shown). Therefore we conclude that $\mathrm{Fb}$ / BDNF cells express and secrete BDNF.

To test whether BDNF secreted by $\mathrm{Fb} / \mathrm{BDNF}$ cells was biologically active, we analyzed the conditioned media from $\mathrm{Fb}$ / BDNF or Fb cells using the standard E8 chicken DRG bioassay. 
As shown in Figure $3 F-H$, both conditioned medium from $\mathrm{Fb}$ / BDNF cells (Fig. $3 G$ ) and commercially available recombinant human-BDNF (Fig. $3 H$ ) induced neurite outgrowth, indicating bioactivity of the BDNF secreted by $\mathrm{Fb} / \mathrm{BDNF}$ cells. Conditioned medium from unmodified fibroblasts failed to induce neurite outgrowth (Fig. $3 F$ ).

To measure the levels of BDNF produced by $\mathrm{Fb} / \mathrm{BDNF}$ cells, we tested their conditioned media using slot blot analysis relative to the levels of control recombinant BDNF. We calculated from the data shown in Figure $3 I$ that $\mathrm{Fb} / \mathrm{BDNF}$ cells secrete BDNF into medium at a rate of $12.8 \mathrm{ng} / 10^{6}$ cells per $24 \mathrm{hr}$, whereas unmodified fibroblasts do not secrete any detectable levels of BDNF.

\section{Spinal cord lesion, transplant survival, and in vivo transgene expression}

Spinal cord tissue from the lesion only and lesion plus transplant groups was examined for lesion extent, the transplant survival, host-graft apposition, and scar tissue formation. In animals that received a Gelfoam implant, 1 month after surgery Gelfoam was reabsorbed, leaving a CSF-filled cyst with collapsed dura (Fig. $4 A$ ). Both types of cell transplants completely filled the lesion cavity in the host spinal cord (Figs. 4B, $C, 5$ ). There was no obvious morphological difference between the two types of grafts. Both consisted of densely packed cells with the morphological characteristics of fibroblasts (Fig. 4E). The donor cells were supported by host blood vessels that are present throughout the transplants (Fig. 4D). The grafts were almost always completely apposed to the host tissue, showing excellent tissue apposition without interruption by cysts (Figs. $4 B-D, 5$ ) or scar tissue at the graft-host interface (Figs. $4 D, 5$ ). The lack of scar tissue was also evident in animals receiving only Gelfoam transplants (Fig. 4A). We attributed the good graft survival and absence of scar formation to the efficient CsA immunosuppression protocols and to the inhibition of inflammation and perhaps prevention of secondary cell death by methylprednisolone (Taoka and Okajima, 1998).

We used X-gal histochemical staining to monitor survival of the donor cells and in vivo transgene expression. Figure 5 presents serial sections from a typical $\mathrm{Fb} / \mathrm{BDNF}$ transplant, showing that the donor cells formed a homogeneous cell column that stained robustly for the presence of $\beta$-galactosidase. Two months after grafting, many cells in the transplant remain $\mathrm{X}$-gal positive, but the staining was much less intense (data not shown). The presence of donor cells in the graft area, at longer survival times, was also verified by their bright bisBenzimide nuclear staining (data not shown).

\section{Host response to the cell transplants}

We used various immunocytochemical markers (Table 2) to analyze the host response to the $\mathrm{Fb}$ or $\mathrm{Fb} / \mathrm{BDNF}$ transplants. In animals receiving $\mathrm{Fb} / \mathrm{BDNF}$ transplants, numerous host axons, stained with a monoclonal neurofilament antibody RT-97, were present throughout the grafts and at the graft-host interface (Fig. $6 B$ ). In contrast, these fibers penetrated $\mathrm{Fb}$ transplants only sparsely and superficially (Fig. 6A). To analyze the source of these penetrating axons, we stained the graft with antibodies for CGRP (Fig. 6C,D), serotonin (Fig. 6E-G), dopamine- $\beta$ hydroxylase $(\mathrm{D} \beta \mathrm{H})$, and choline acetyltransferase (ChAT). We also stained for the presence of BDA anterogradely labeled RST axons in the graft (described in the next section). CGRP- (Fig. $6 C, D$ ), serotonin- (Fig. 6E-G), and BDA-labeled (see Figs. 9, 10) fibers were present in the $\mathrm{Fb} / \mathrm{BDNF}$ transplants, indicating axon ingrowth from dorsal root, raphe nuclei, and RN. Most serotonin
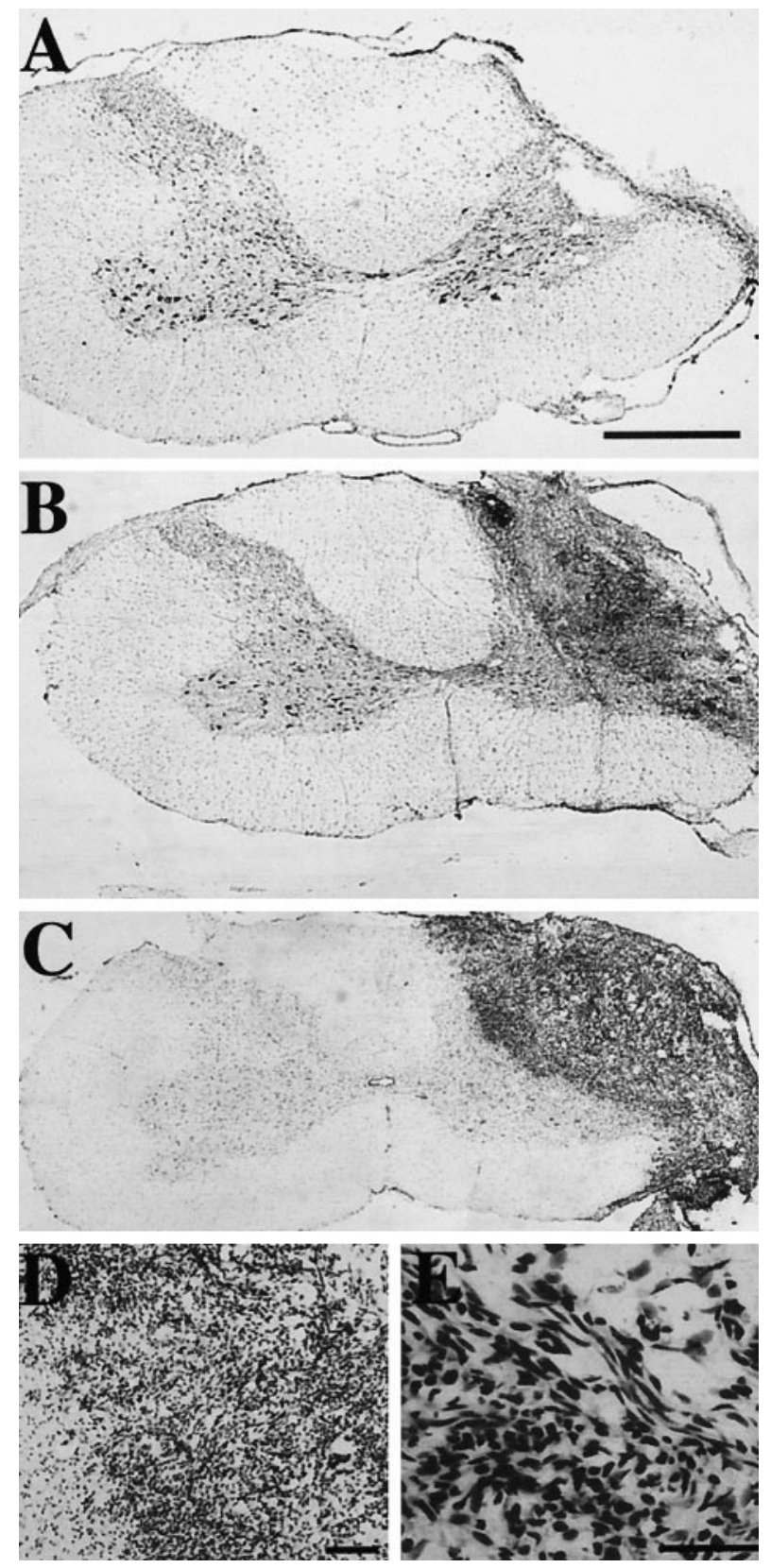

Figure 4. Photomicrographs of cervical spinal cord sections showing lesion and transplant in different animal groups. Animals received a right C3-4 partial hemisection and a transplant of Gelfoam $(A), \mathrm{Fb}(B)$, or $\mathrm{Fb} / \mathrm{BDNF}(C)$. The animals were killed 1 month after surgery. Spinal cord tissue was cut into cross sections and stained with cresyl violet. $D, E$, High-power images of $C$ showing the host-graft interface $(D)$ and the characteristic morphology of fibroblasts in the transplants $(E)$. Scale bars: $A-C, 500 \mu \mathrm{m} ; D, E, 100 \mu \mathrm{m}$.

input is known to originate from raphe nuclei, and the projection is bilateral; therefore, the extent to which serotoninimmunoreactive profiles represented regenerating axons or sprouting from unlesioned local axons cannot be distinguished. ChAT-or $\mathrm{D} \beta \mathrm{H}$-positive axons were present in the host tissue near, but not in, either type of transplant (data not shown).

To characterize the host immune response, we performed additional immunocytochemical studies, using anti-GFAP antibody to identify astrocytes (Fig. $7 A, B$ ), OX-42 antibody to identify microglia and macrophages (Fig. $7 C, D$ ), and ED-1 antibody 


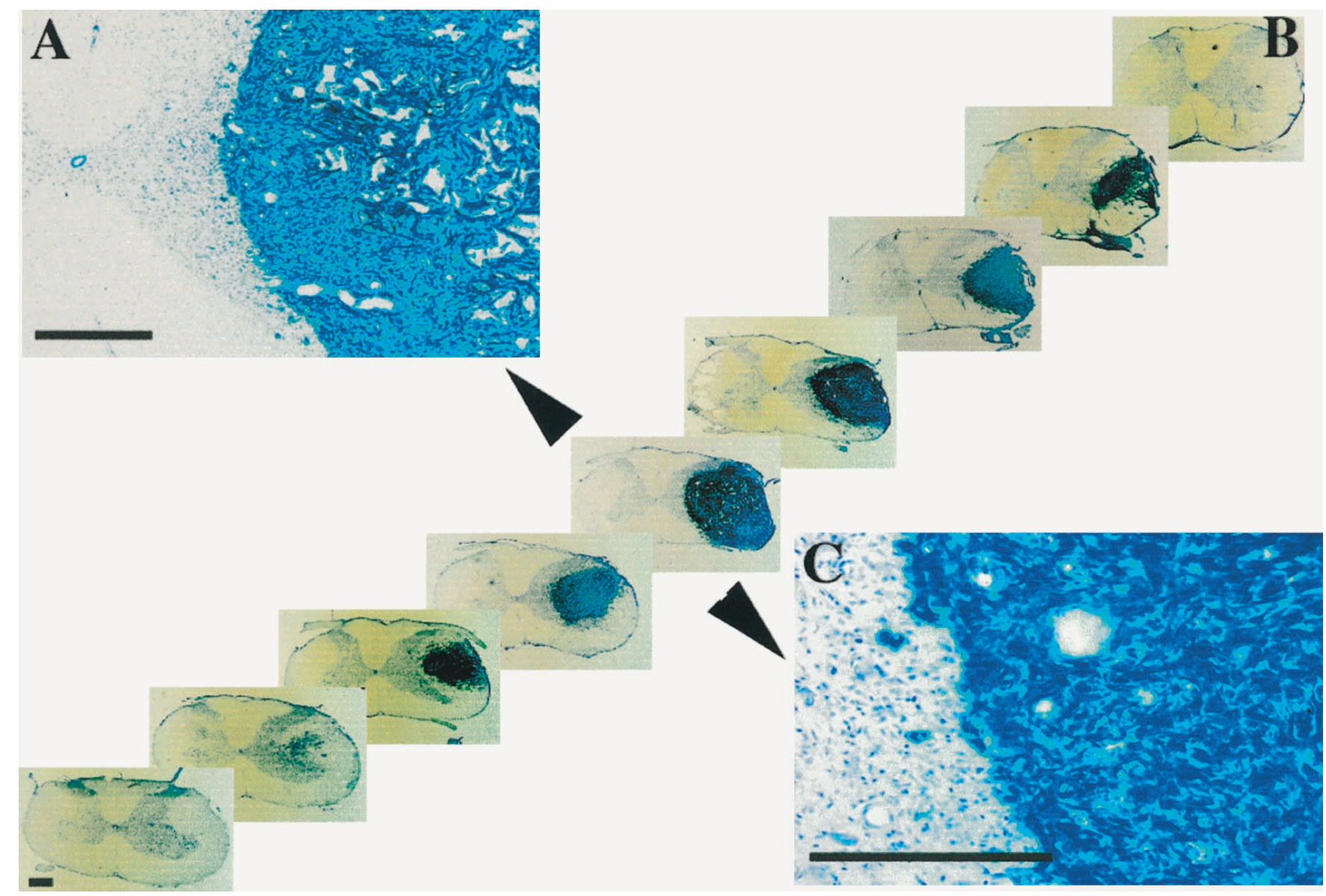

Figure 5. Photomicrographs of cervical spinal cord sections showing transgene expression in $\mathrm{Fb} / \mathrm{BDNF}$ transplants. Animals received a right $\mathrm{C} 3-4$ partial hemisection and a transplant of $\mathrm{Fb} / \mathrm{BDNF}$ cells. Serial sections of spinal cord tissue were stained with X-gal histochemistry and lightly counterstained with cresyl violet. In $B$, the sections (spaced by $500 \mu \mathrm{m}$ ) were serially reconstructed to show the extent of the lesion and the transplant. $A, C$, High-power images from $B$ (arrowheads). $A$, Host-graft interface and numerous blood vessels in the transplant. $C$, Host-graft integration and the intense X-gal staining, suggesting high levels of transgene expression. One week survival. Scale bars: $A, C, 200 \mu \mathrm{m} ; B, 500 \mu \mathrm{m}$.

to identify activated microglia and macrophages (Fig. 7E,F). These studies demonstrated astrocytes, macrophages, and microglia on the border of the transplants but not within (Fig. 7). Glial scar formation around the grafts was modest (Fig. $7 A, B$ ). The immune response at the graft-host interface and within the grafts was similar in the three groups of animals with Gelfoam, Fb, or $\mathrm{Fb} / \mathrm{BDNF}$ transplants, probably because they received the same immunosuppression treatment.

\section{RST anterograde tracing with BDA}

To study whether cell transplants induced regeneration from axotomized RN neurons, we determined the distribution of RST axons after injection of the anterograde tracer BDA into the magnocellular portion of the lesioned RN. This tracer was chosen because of the high resolution, which enables identification of axons (Brosamle and Schwab, 1997; Z'Graggen et al., 1998). Figure 8 shows the location of RST axons in normal animals. In the cervical region, the RST axons occupy a wedge-shaped area in the superficial dorsolateral white matter. The medial border of the tract is separated from the dorsal gray matter by a narrow band of $\sim 100 \mu \mathrm{m}$, which includes axons of the spinocervical tract (Fig. 8) (Brown, 1974). Ventrally the RST reaches approximately to the level of the base of the dorsal horn, although a few scattered axons are positioned lateral to the ventral horn (Fig. 8). Axonal branches arise perpendicular to parent RST axons and enter lam- inae V-VII of the gray matter. These results are consistent with previous studies (Waldron and Gwyn, 1969; Brown, 1974; Tracey, 1995). Both DAB and FITC labeled the BDA-traced axons efficiently, but DAB offered greater resolution and revealed smallcaliber axons that were not visible by FITC stain (data not shown). However, FITC was superior to DAB when observing spinal cord cross sections because it more readily distinguished axons from red blood cells and allowed the host and graft to be distinguished on the basis of a fluorescent image without a counterstain.

To visualize the regenerated RST axons in the lesiontransplant region, cross, sagittal, and horizontal sections were stained for the presence of BDA-labeled fibers. As shown in Figures 9 and 10, the spinal cord lesion completely disrupted the right RST. Numerous BDA-labeled RST axons had regenerated into the transplant (Fig. $9 A-C$ ). Many axons cut in cross section were present along the host-graft interface (Fig. 9D), and axon branches (sectioned longitudinally) entered the gray matter (Fig. $9 E$ ). Double-labeling with FITC-avidin and GFAP immunofluoresence demonstrated that axons at the host-graft interface intermingled with processes of activated astrocytes (Fig. 9F-H). FITC staining underestimated the number of RST axons that regenerated into the transplants because most of them were smaller-caliber axons and not well stained by FITC (Fig. 10I,J). Sagittal and horizontal spinal cord sections (Fig. 10) confirmed 

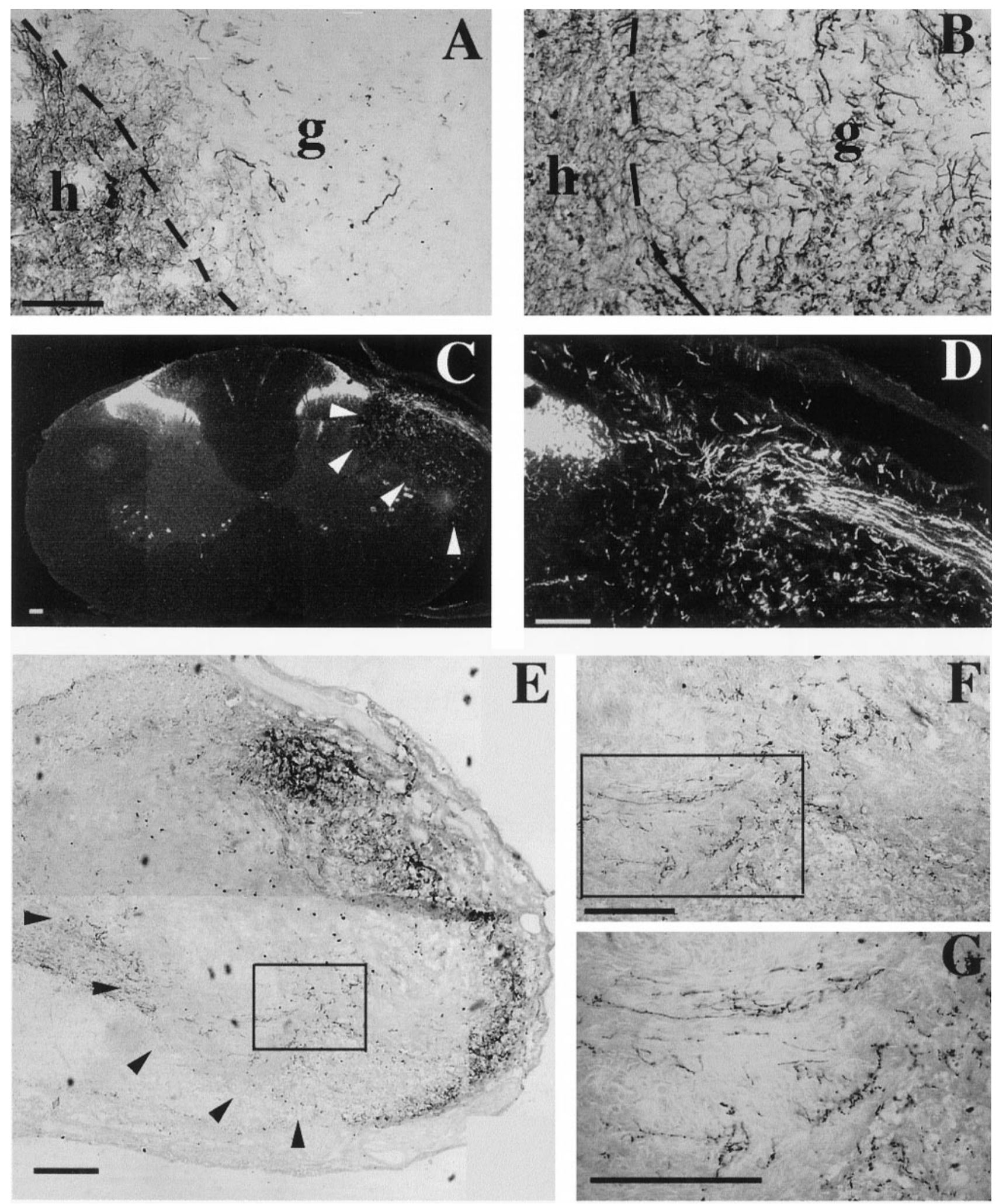

Figure 6. Photomicrographs of cervical spinal cord sections showing host axon growth into Fb/BDNF or Fb transplants. Spinal cord cross sections from animals receiving $\mathrm{Fb}(A)$ or $\mathrm{Fb} / \mathrm{BDNF}(B)$ transplants were stained with the RT-97 antibody and show cell grafts $(g)$, the host gray matter $(h)$, and the host-graft interface (dashed lines). Numerous axons are present within the $\mathrm{Fb} / \mathrm{BDNF}$ transplant and at the host-graft interface $(B)$, whereas host axons penetrate $\mathrm{Fb}$ transplant sparsely and superficially $(A)$. One month survival. Scale bars, $100 \mu \mathrm{m}$. In $C$ and $D$, a spinal cord cross section from a Fb/BDNF recipient was stained with an anti-CGRP antibody. A dorsal root had regenerated into the transplant and elongated toward the dorsal horn, which was partially disrupted by the transplantation procedures, as intended. Arrowheads outline the graft. $D$, Higher-power view of axons that had reached the dorsal horn. Two month survival. Scale bars: $C, 200 \mu \mathrm{m} ; D, 100 \mu \mathrm{m}$. In $E-G$, a spinal cord cross section from an Fb/BDNF recipient was stained with an anti-serotonin antibody. Numerous serotonin-immunoreactive fibers are present throughout the transplant $(E)$. At higher power $(F, G)$, the axons show the characteristic "beads on a string" morphology. In $E$ arrowheads outline the graft-host interface. One month survival. Scale bars, $100 \mu \mathrm{m}$. 

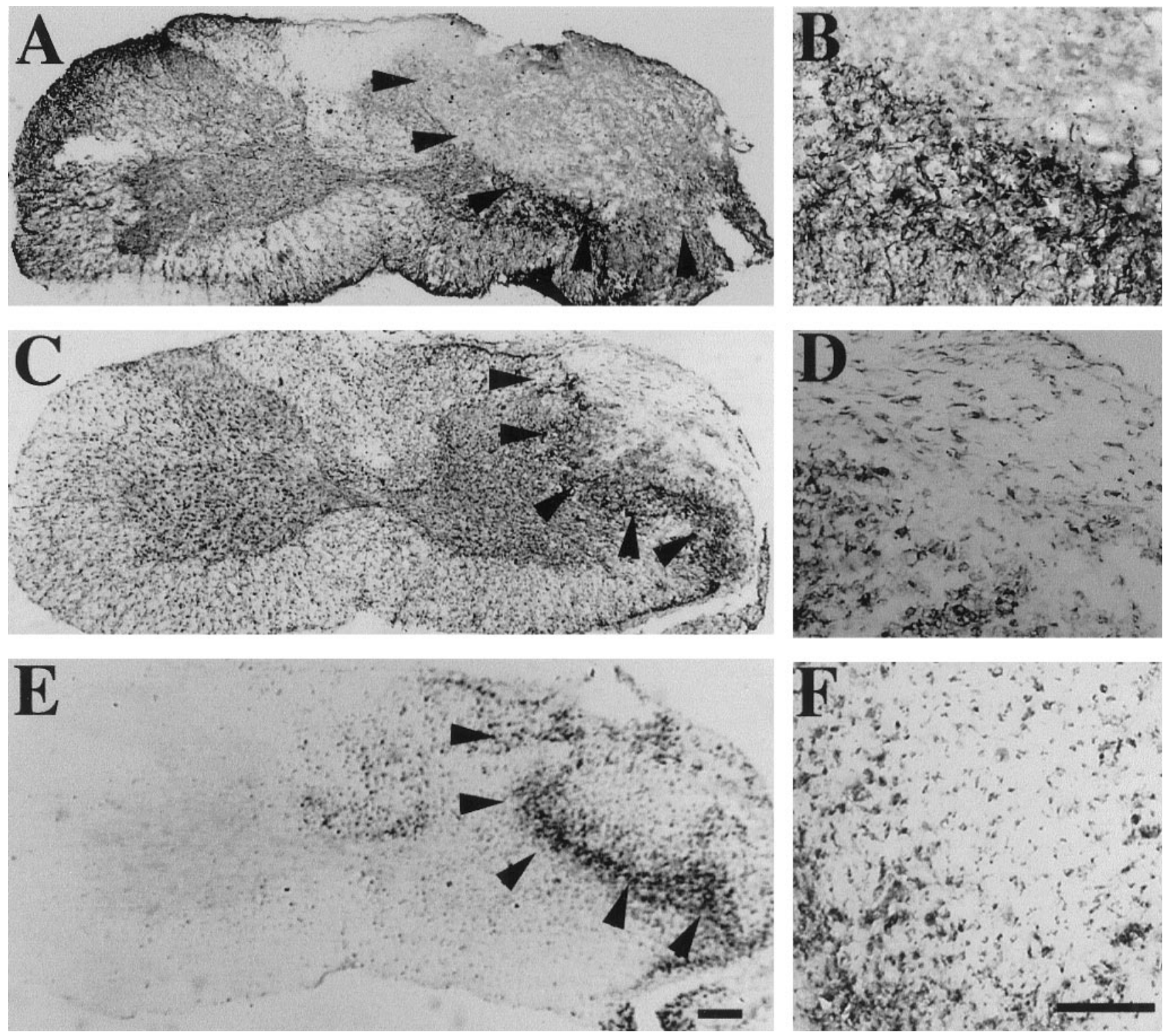

Figure 7. Photomicrographs of cervical spinal cord sections showing host immune response. Spinal cord cross sections from animals receiving $\mathrm{Fb} / \mathrm{BDNF}$ transplants were immunostained with $\operatorname{GFAP}(A, B)$, OX-42 $(C, D)$, and ED-1 $(E, F)$ antibodies. A mild astrocytic activation is visible along the graft-host interface, but few if any astrocytes are in the graft $(A, B)$. Macrophages and activated microglia accumulate at the graft-host interface, but few are in the transplants $(C-F)$. One month survival. Scale bars, $100 \mu \mathrm{m}$.

that the spinal cord lesion disrupted the entire RST and that all of the axotomized axons stopped at the host-graft border in recipients of unmodified fibroblasts (Fig. 10 $\mathrm{A}$ ). Some of the axons, however, had grown across the interface of $\mathrm{Fb} / \mathrm{BDNF}$ transplants (Fig. 10B,D,H), elongated caudally (Fig. $10 B, E, H, I, J)$, and exited the graft at the caudal graft-host interface (Fig. $10 F-H)$. Although many larger-caliber axons stopped at the host-graft border, numerous small-caliber axons continued directly into the transplant (Fig. $10 I, J)$.

Serial sections of spinal cord caudal to the grafts were studied to determine the caudal extent of regenerated BDA-labeled axons and their path of regeneration. Numerous transversely sectioned, BDA-labeled axons had regenerated to the upper thoracic spinal cord, which was four to five segments caudal to the transplant, but their number was small compared with normal. Regenerating axons were diffusely located and not as well organized as the normal RST axon. Most of them were localized to the white matter, but a few were present in the gray matter. In general the location of the regenerated RST axons deviated only slightly from normal (Fig. 11, compare $A, B$ ), although in some cases BDAlabeled axons were present diffusely throughout the ipsilateral lateral funiculus (data not shown). Axonal branches arising perpendicular to the main stem frequently projected toward laminae V-VII of the gray matter (Fig. $11 B-D$ ) and bore small terminal bouton-like varicosities (Fig. 11C,D), similar to those observed previously on corticofugal axons labeled with BDA (Z'Graggen et al., 1998). Many of these branches grow toward interneurons in the gray matter, and the terminal bouton-like structures were close to these neurons (Fig. 11C). The maximum length of RST regeneration and the number and distribution of regenerating axons differed among animals. Similar findings were reported by other investigators studying CST regeneration (Schnell and 

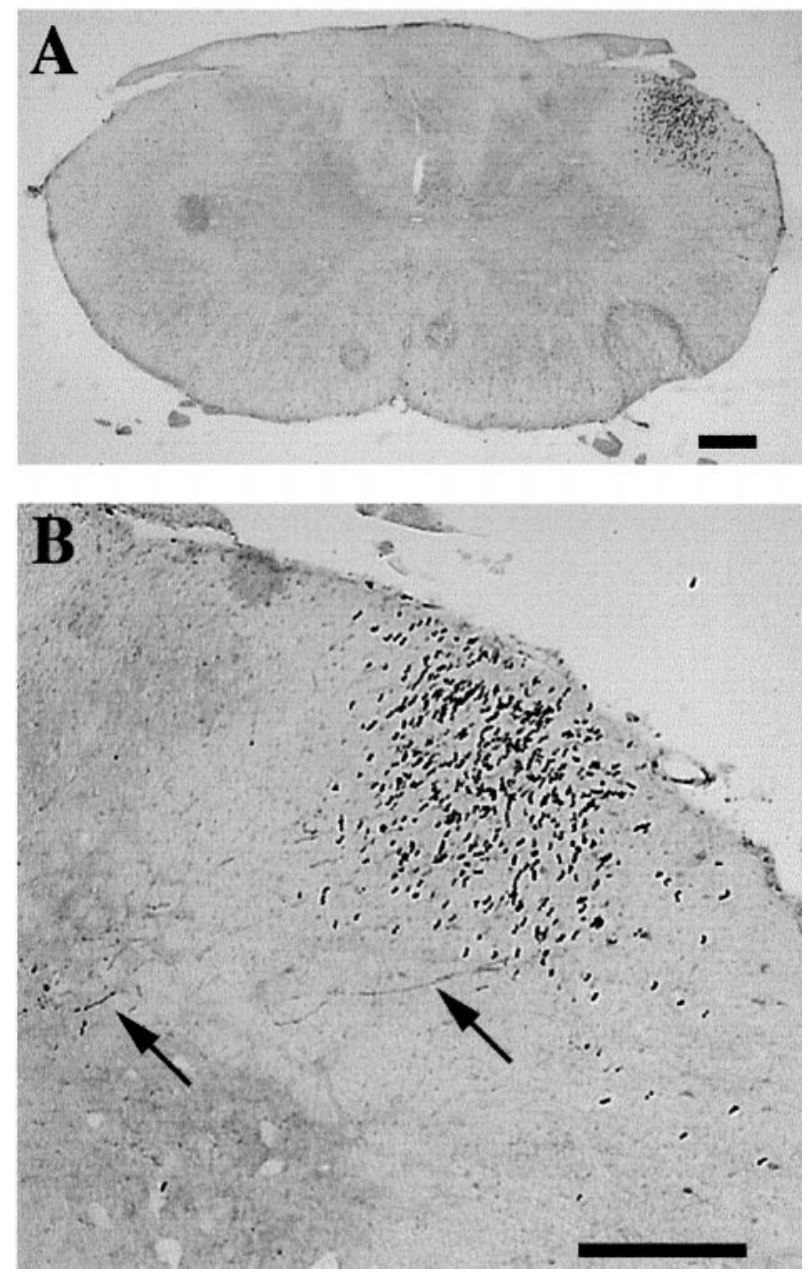

Figure 8. Photomicrographs of cervical spinal cord sections showing the distribution of the RST in normal animals after BDA anterograde tracing. BDA was injected into the maganocellular portion of the left RN. Cervical spinal cord sections were stained with $\mathrm{DAB}$ and demonstrate the discrete location of RST in the superficial dorsolateral quadrant $(A)$. $B$, Higher-power view of the morphology and organization of RST axons. In $B$ arrows point to axon branches in the gray matter. Scale bars, $100 \mu \mathrm{m}$.

Schwab, 1990; Bregman et al., 1995). We do not know the reasons for these differences, but we speculate that they may be attributable to differences in interactions between the grafts and hosts. Among the 12 animals that received $\mathrm{Fb} / \mathrm{BDNF}$ grafts and BDA tracing (Table 1, Experimental group I), four of the six 1 monthsurvival animals showed BDA-labeled axons caudal to the transplant: one animal to low cervical, two animals to upper thoracic, and one animal to mid thoracic levels. The rate of RST axon regeneration was estimated to be $1-1.5 \mathrm{~mm} / \mathrm{d}$. Examination of the lesion-transplant site confirmed the completeness of the lesion and the presence of healthy grafts. Because two animals that showed no BDA labeling in the caudal spinal cord also had no labeling in the CNS tissue rostral to the transplant, the apparent failure of RST regeneration in these animals may therefore have been attributable instead to the failure of the tracing technique. Three of the six 2 month-survival animals (Table 1, Experimental group I) showed BDA labeling similar to the four 1 monthsurvival animals, with the most caudal levels that contained BDA-positive fibers being upper to mid thoracic. Therefore the extent of RST regeneration (the most caudal spinal cord level in which BDA-labeled axons is detected) showed no consistent difference between the 1 and 2 month groups. Three of the 2 month-survival animals were eliminated from the study because in one the lesion was incomplete, one lacked a transplant, and in the third the tracing technique failed. In animals receiving $\mathrm{Fb}$ or Gelfoam transplants, few if any BDA-labeled axons were present either in the transplants or at the host-graft interface. No BDApositive axons were detected caudal to the transplant (data not shown). In animals receiving $\mathrm{Fb} / \mathrm{BDNF}$ transplants, RST axons rostral to the transplants also showed a considerable amount of sprouting (Fig. 10B,C), whereas sprouting was minimal in control animals (Fig. 10A).

\section{RST retrograde tracing with FG}

We also studied RST regeneration using the FG retrograde tracing technique. The FG was injected bilaterally three to four segments $(1-1.5 \mathrm{~cm})$ caudal to the transplant to avoid diffusion of FG into the transplant. We nevertheless found FG in several grafts, probably because of diffusion via the CSF, and these animals were consequently eliminated from the study. Figure $12 A-C$ showed the typical pattern of RSN labeling after bilateral injections of FG into the low cervical region of normal rats. The injections labeled both red nuclei equally. In animals with a right-sided lesion and Gelfoam transplant, no labeled cells were present in the left $\mathrm{RN}$, whereas labeling in the right $\mathrm{RN}$ resembled that of normal animals (Fig. $12 D-F$ ). In animals receiving a lesion and $\mathrm{Fb}$ graft, FG labeling was infrequently observed in the contralateral RN (Fig. 12G-I). In contrast, in $\mathrm{Fb} / \mathrm{BDNF}$ recipients numerous neurons were brightly labeled by FG throughout the rostrocaudal extent of the axotomized RN (Fig. 12J-L). The number of FG-labeled RN neurons was counted in all four groups of animals (Fig. 13). In normal animals, 3000 neurons were labeled in each RN. After cervical axotomy and Gelfoam implant, $\sim 10$ cells were labeled in the contralateral $\mathrm{RN}$; these cells may represent neurons that project ipsilaterally $(<1 \%$ of total $\mathrm{RSN})$. With Fb transplant, 30-40 cells were retrogradely labeled in the contralateral RN. Although this number was not significantly different from that of animals receiving only Gelfoam implants, Fb grafts may have provided a permissive environment that allowed a very small percentage of axotomized neurons to regenerate to the caudal spinal cord. Approximately 175-200 neurons were labeled in the contralateral $\mathrm{RN}$ in the presence of $\mathrm{Fb} / \mathrm{BDNF}$ grafts. This number represents $7-10 \%$ of the total RN neuron population (Fig. 13). The number of labeled neurons in animals with 2 month-survival was not significantly different from that of the 1 month-survival animals for any of the groups (Fig. 13).

Fetal spinal cord transplants secure a partial rescue of RN neurons injured by a C3-4 axotomy but fail to prevent their atrophy (Mori et al., 1997). To analyze whether cell atrophy also occurred in the regenerated RN neurons, the cross-sectional area of FG-labeled RN neurons was measured and compared across experimental and control groups. We found no difference among them, indicating that the regenerated $\mathrm{RN}$ neurons had not atrophied in animals receiving $\mathrm{Fb} / \mathrm{BDNF}$ or $\mathrm{Fb}$ transplants (data not shown). The normal soma size of the few FG-labeled neurons in Gelfoam recipients was not surprising because these neurons probably project ipsilaterally and were not axotomized.

\section{Behavior analysis}

When placed in a cylinder, normal rats spontaneously reared and explored the wall of the cylinder using a single forepaw alone $(50 \%)$ or both forepaws together $(50 \%)$. We calculated the percentage of wall exploratory behavior that was initiated by right or 

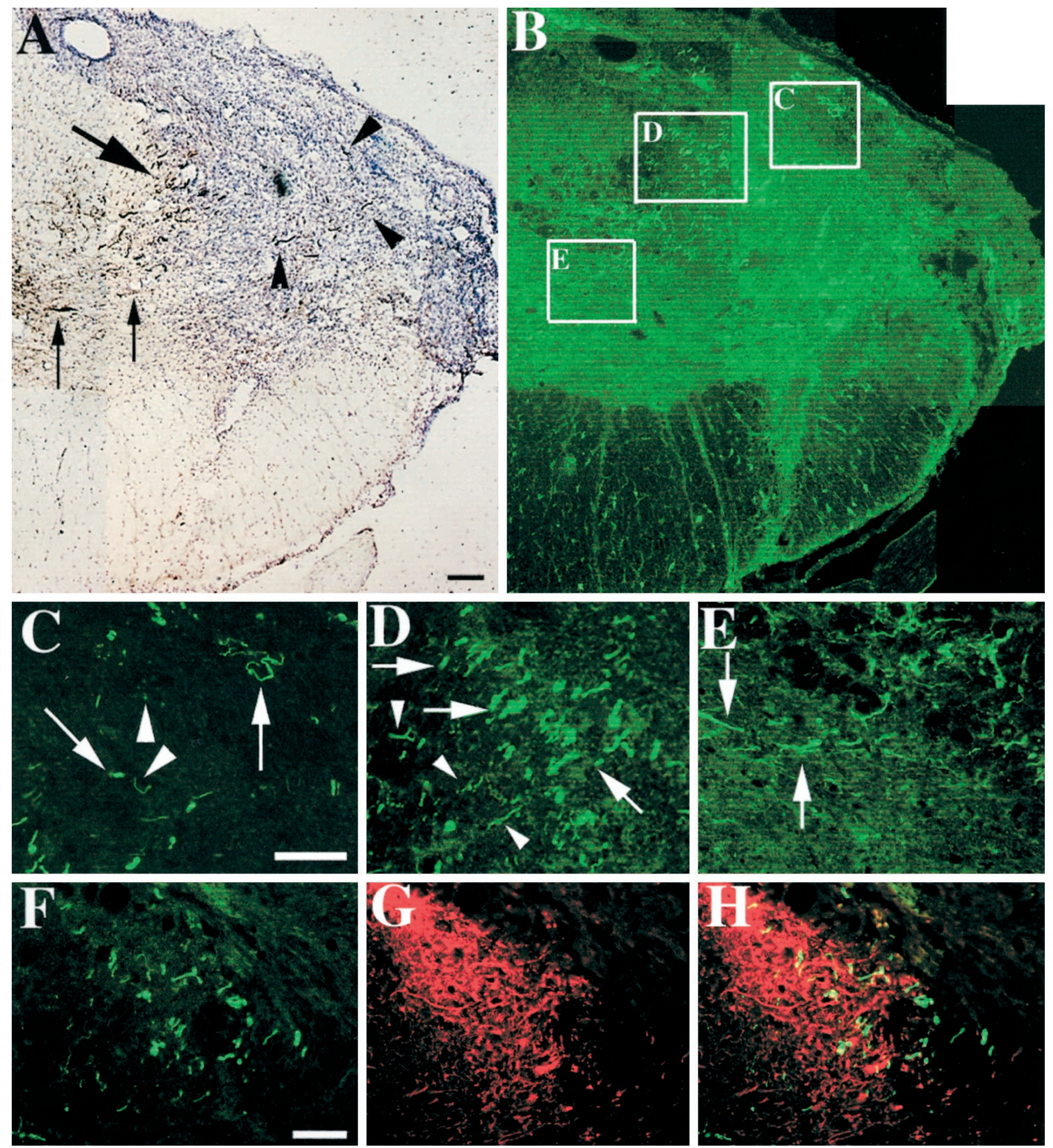

Figure 9. Photomicrographs of cervical spinal cord sections showing BDA anterograde tracing of RST axons in the lesion-transplant site. The animal received a right cervical hemisection and an $\mathrm{Fb} / \mathrm{BDNF}$ transplant. The left $\mathrm{RN}$ was anterogradely traced with BDA $15 \mathrm{~d}$ before killing. Two month survival after transplantation. $A$, Section through the transplant $1000 \mu \mathrm{m}$ from its rostral pole. The section was stained with DAB as chromagen for BDA-labeled fibers and counterstained with cresyl violet. Numerous BDA-labeled axons are present in the transplant (arrowheads) and at the graft-host interface (large arrow) and send off branches into the gray matter (small arrows). However, most of the BDA-labeled axons are obscured by the counterstain. $B$, Adjacent section stained with FITC to identify BDA-labeled fibers, no counterstain. $C-E$, Higher magnification of the corresponding regions in $B$. C, Numerous BDA-labeled axons in the transplant. Most are cut transversely. Arrowheads point to smaller-caliber axons, and arrows point to larger-caliber axons. In $D$, many transversely sectioned larger-caliber axons are labeled at the graft-host interface (arrows) and send off branches perpendicular to the main stem toward the gray matter (arrowheads). E. Higher-power view of axon branches that enter the gray matter (arrows). $F-H$, Section double-labeled with FITC-avidin $(F)$ and an anti-GFAP antibody $(G)$. $H$, Merged image of $F$ and $G$. Numerous RST axons are intermingled with processes of activated astrocytes. Scale bars: $A, 200 \mu \mathrm{m} ; C, F, 100 \mu \mathrm{m}$. Scale bar in $A$ applies to $B$; scale bar in $C$ applies to $D$ and $E$; scale bar in $F$ applies to $G$ and $H$. 

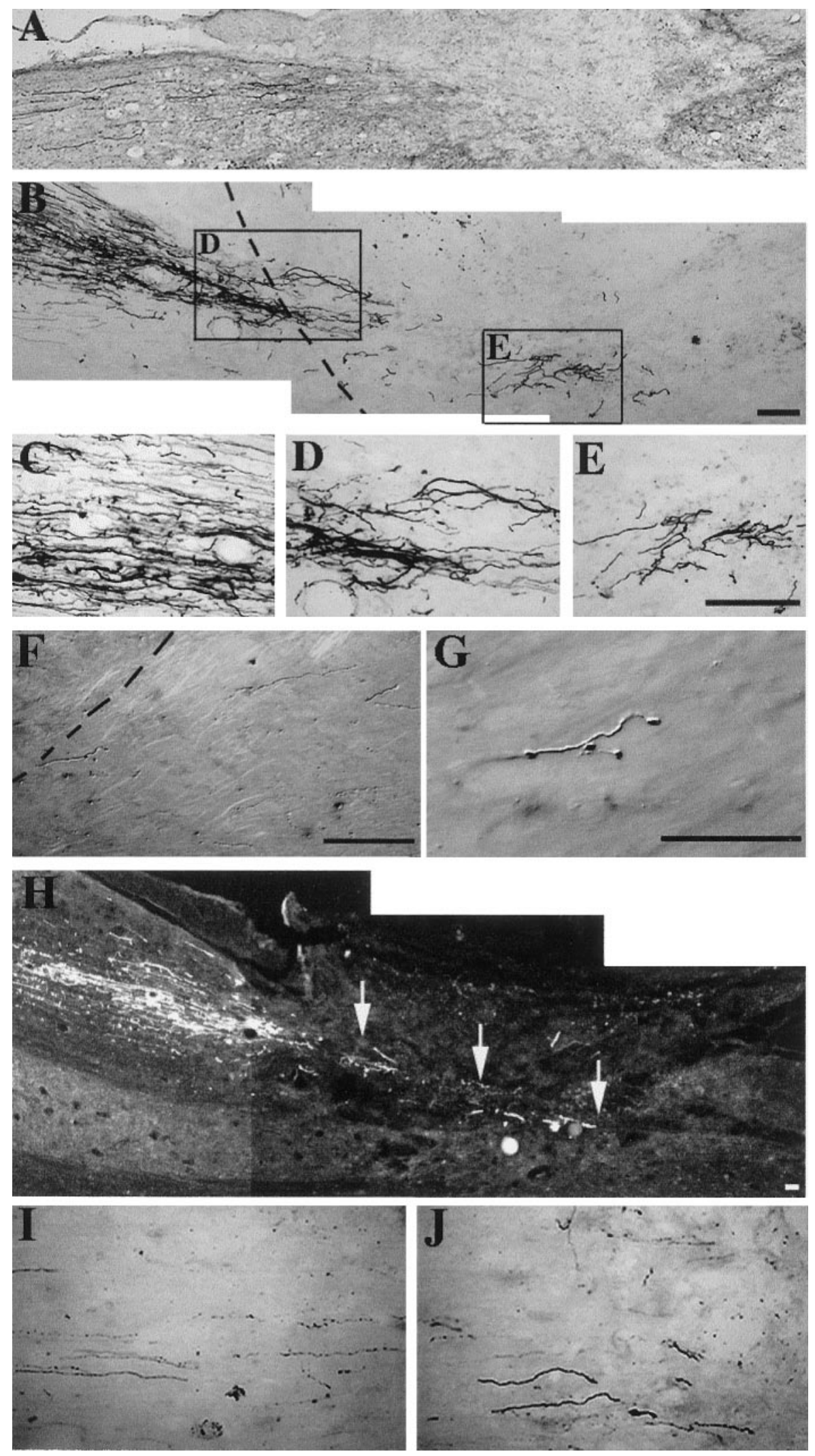

Figure 10. Photomicrographs of cervical spinal cord sections showing regeneration of RST axons through $\mathrm{Fb} / \mathrm{BDNF}$ transplants. Animals received a right cervical hemisection and $\mathrm{Fb}(A)$ or $\mathrm{Fb} /$ BDNF transplants $(B-J)$. The left RN was anterogradely traced with BDA $15 \mathrm{~d}$ before killing. One month survival after transplantation. Spinal cord tissue was cut into sagittal $(A-H)$ or horizontal ( $I$, $J)$ sections. For all sections left is rostral, and right is caudal. $A$, All BDA-labeled RST axons are interrupted by the lesion-transplant and failed to enter an $\mathrm{Fb}$ transplant. $B$, Some RST axons regenerated into an $\mathrm{Fb} / \mathrm{BDNF}$ transplant; the dashed line indicates the rostral graft-host interface. $C$, Region rostral to the transplant. Numerous axon branches are evident, suggesting sprouting induced by the transplant. $D, E$, Higher magnifications of regions from $B . D$, BDA-labeled axons that have penetrated the rostral graft-host interface. $E$, RST axons deeply within the transplant. $F$, Region in the host white matter immediately caudal to the transplant. The dashed line indicates the caudal graft-host interface. BDA-labeled axons exit the transplant and elongate caudally. Some axons bear varicosities resembling terminal boutons. $G$, Terminal bouton-like structure at higher power. $H$, BDA-labeled axons stained by FITC. Regenerated axons (arrows) pass through the rostral graft-host interface and continue for several millimeters through the transplant and the caudal graft-host interface. $I, J$, Higher-power views of many smaller-caliber and some larger-caliber RST axons in a rostrocaudal direction in an $\mathrm{Fb} / \mathrm{BDNF}$ transplant. Scale bars, $100 \mu \mathrm{m}$. The scale bar in $E$ applies to $C, D, I$, and $J$. left forepaws alone or both forepaws together (see Fig. 15). Hemisection at the upper cervical level produced asymmetry in forelimb use; hemisected rats or rats with nonmodified transplants rarely used the forelimb ipsilateral to the injury and did not show recovery during the 8 -week observation period (Figs. $14 C$, $15 A$ ). Animals with $\mathrm{Fb} / \mathrm{BDNF}$ transplants used the injured forelimb more frequently than the hemisection or $\mathrm{Fb}$ alone groups, resulting in more symmetrical limb use (Figs. 14A, 15A). At 1 


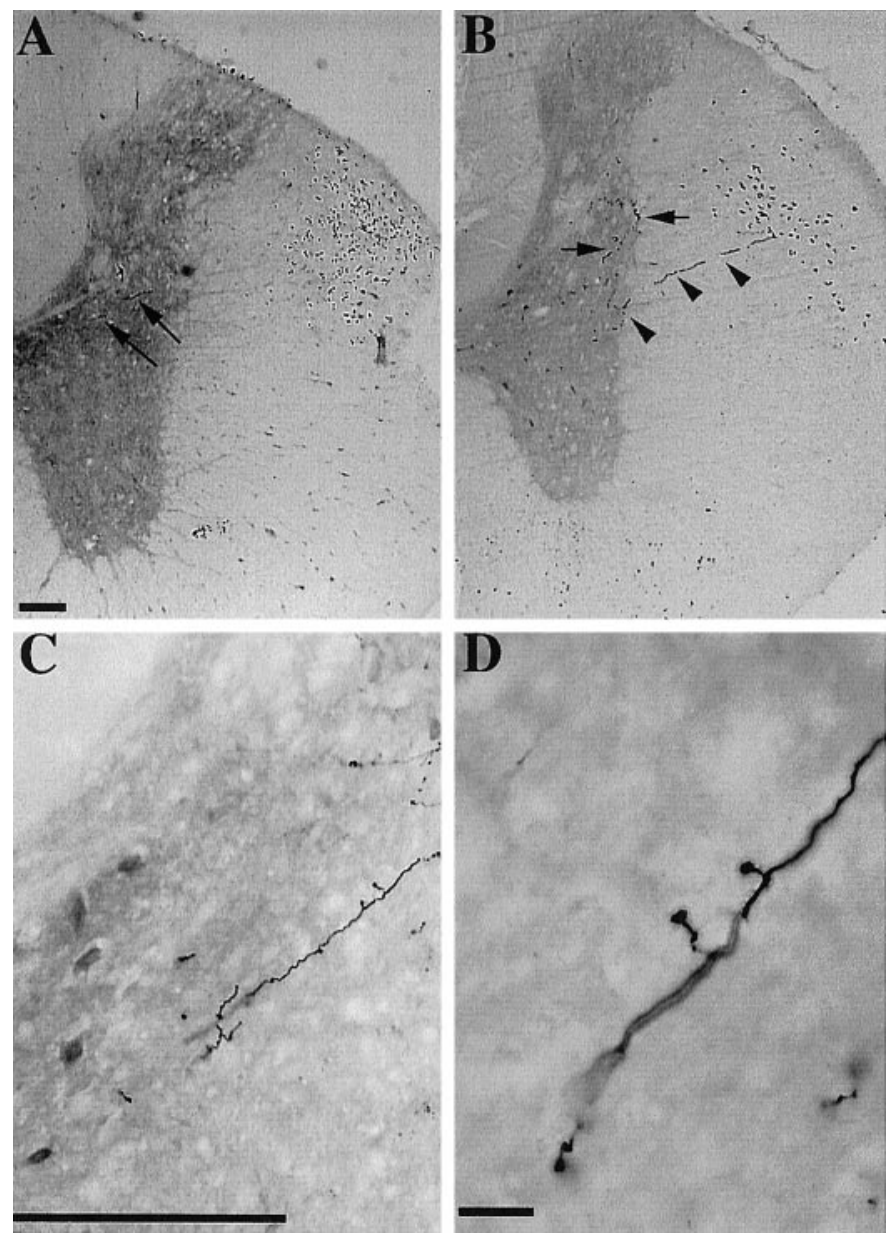

Figure 11. Photomicrographs of upper-thoracic $(A, B)$ and mid-thoracic $(C, D)$ spinal cord showing BDA-labeled RST axons. $A$, Cross section from a normal animal demonstrating the normal RST location and organization. Arrows point to axon branches in the gray matter. B, Cross section from an animal with an $\mathrm{Fb} / \mathrm{BDNF}$ transplant. One month survival. Numerous BDA-labeled axons are present in the lateral funiculus, but their location is aberrant and more diffuse than normal. A few transversely sectioned BDA-labeled axons are also present in the gray matter (arrows). One axon branch arises perpendicular to the main stem and enters lamina VII (arrowheads). C, Axon branches in the gray matter with varicosities resembling terminal boutons. $D$, Terminal bouton-like structures at higher power. Scale bars: $A-C, 100 \mu \mathrm{m} ; D, 25 \mu \mathrm{m}$. Scale bar in $A$ also applies to $B$.

week after surgery, both $\mathrm{Fb}$ and hemisection control animals used only the unaffected forelimb (contralateral to lesion) in exploring the wall $(p<0.05)$. The $\mathrm{Fb} / \mathrm{BDNF}$-treated rats performed much of the exploration with the good limb, but they also used both forelimbs together $\sim 10 \%$ of the times. This suggests that although the animals did not use the affected limb independently, they could use it to support the unaffected limb as early as the first week after surgery. By 2 weeks, the Fb/BDNF-treated animals used both forelimbs together as often as they used the unaffected forelimb alone $(p>0.05)$, indicating further recovery. We observed a similar pattern of limb use at 3 weeks after surgery, except that rats with $\mathrm{Fb} / \mathrm{BDNF}$ transplants sometimes used the limb ipsilateral to the lesion alone. Approximately 5\% of the total movements were made by the ipsilateral forelimb alone in the $\mathrm{Fb} / \mathrm{BDNF}$ group, whereas neither the $\mathrm{Fb}$ nor the hemisection group animals used that forelimb independently. By 4 and 8 weeks after surgery, some of the animals in the $\mathrm{Fb} / \mathrm{BDNF}$ group used the ipsilateral forelimb alone $\sim 10 \%$ of the time. In addition, control (hemisection and Fb transplant) groups held the forepaw ipsilateral to the lesion in a strongly flexed position (Fig. 14C), whereas the posture was closer to normal in animals with $\mathrm{Fb}$ / BDNF transplants (Fig. 14A). These results clearly demonstrate functional recovery of injured limb usage in the $\mathrm{Fb} / \mathrm{BDNF}$ group; improvement was present by 1 week after transplant and reached a plateau between week 3 and 4 . Control groups did not recover (Fig. 15A).

To study whether functional recovery was mediated by regenerated RST axons, animals in Experimental group II (Table 1) were subjected to a second lesion that removed the right dorsolateral quadrant at $\mathrm{C} 2$ just rostral to the transplant. Forelimb function was then tested for another 5 weeks. The second lesion almost completely abolished the recovered function in $\mathrm{Fb} / \mathrm{BDNF}$ animals (Figs. 14B, 15B) but had little effect on the $\mathrm{Fb}$ or Gelfoam recipients (Figs. 14D, 15B). The second lesion also caused animals receiving $\mathrm{Fb} / \mathrm{BDNF}$ transplants to lose their nearly normal forepaw posture and to hold the forepaw ipsilateral to the lesion in a strongly flexed position similar to that of $\mathrm{Fb}$ and Gelfoam animals (Fig. 14A,B), The second lesion had little effect on forepaw posture of $\mathrm{Fb}$ and Gelfoam recipients (Fig. 14C,D).

\section{DISCUSSION}

In the present study we report that intraspinal transplants of primary fibroblasts genetically modified to express BDNF enhanced regeneration of the RST. When grafted into a cervical spinal cord lesion, the donor cells survived well and expressed the transgenes for at least 2 months. The axons of at least $7 \%$ of the severed RN neurons regenerated through and around the transplants, extended for long distances in the white matter caudal to the transplant, and sent off axon branches to normal RST target regions. Behavioral testing revealed significant functional recovery in limb usage, which may be partially mediated by the RST regeneration. In contrast, we found no anatomical or behavioral evidence for RST regeneration in animals that received Gelfoam or unmodified fibroblast transplants.

\section{Critical elements that allow RST regeneration}

Several features of the grafts and their interaction with the host are likely to have contributed to RST regeneration. First, the excellent graft survival and tissue apposition provided the regenerating RST axons with a continuous terrain for growth. A well integrated substrate has been considered of critical importance for regeneration (Bregman et al., 1997). Almost all of the transplants entirely filled the lesion cavity, were intimately apposed to the host tissue, and thus formed an interface with the host that was not interrupted by cysts or scars. The absence of scar formation may reflect the mild host immune reaction attributable to immunosuppression by CsA and the neuronal protective effects of methylprednisolone and BDNF (Novikova et al., 1996). The mild astrocytic activation and accumulation of macrophages and activated microglia along the host-graft interface may also have provided a favorable substrate for regenerating RST axons. We found numerous BDA-labeled RST axons at the graft-host interface and intermingled with processes of activated astrocytes. Activated CNS immunocompetent cells have been proposed to act as permissive substrates for regenerating axons (Kawaja and Gage, 1991; Davies et al., 1997; Prewitt et al., 1997; Rabchevsky and Streit, 1997).

The second crucial feature was the relatively permissive environment provided by the fibroblast grafts (Tuszynski et al., 1994; 

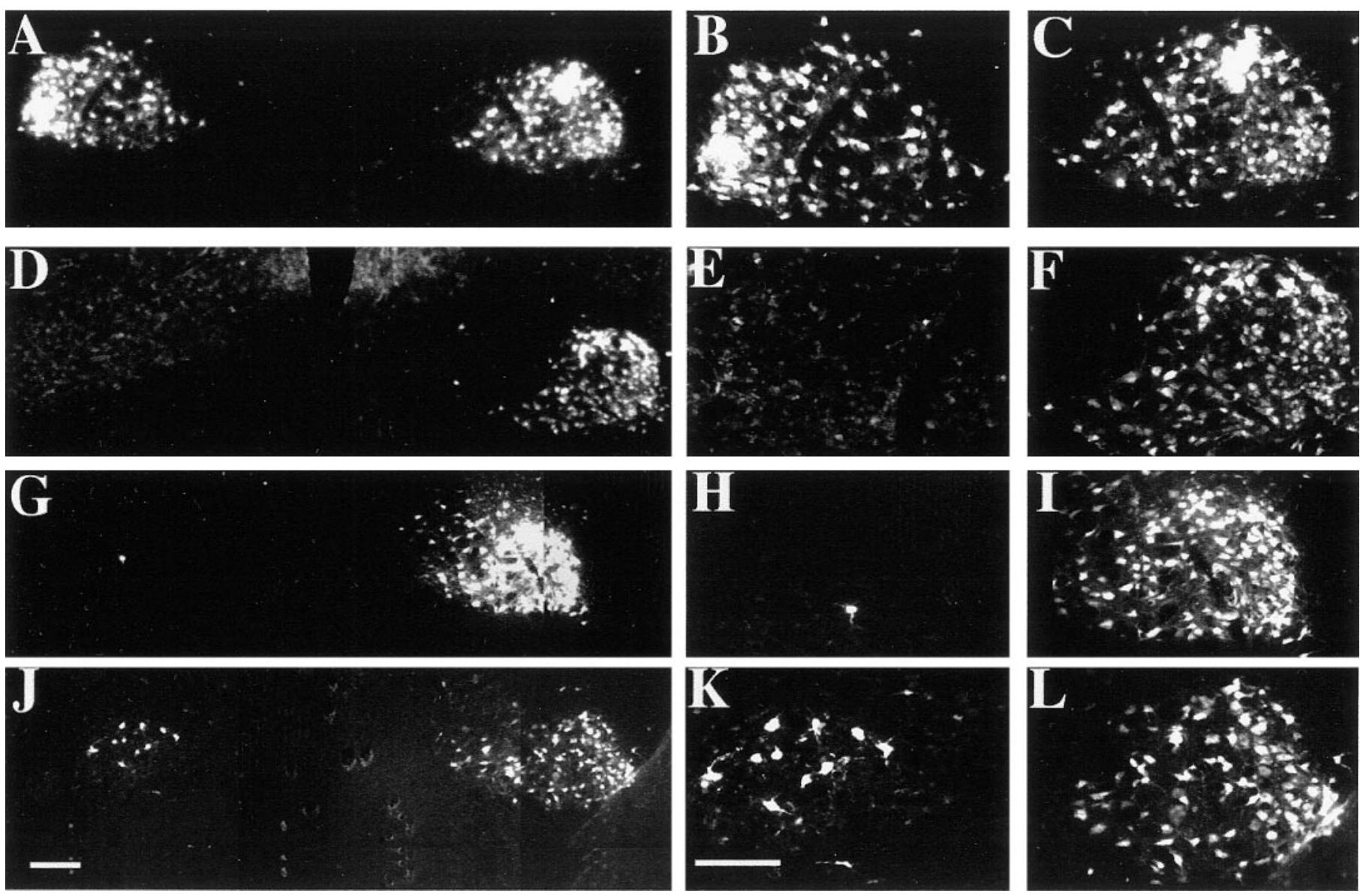

Figure 12. Photomicrographs of midbrain showing FG retrograde tracing of RN neurons. Neurons in both RNs were retrogradely traced by injection of FG into both sides of the spinal cord in normal animals $(A-C)$ or in recipients of Gelfoam $(D-F), \mathrm{Fb}(G-I)$, or Fb/BDNF $(J-L)$ transplants. Survival after transplantation was 1 month. All sections were taken $\sim 480 \mu \mathrm{m}$ from the caudal pole of RN. $B, E, H, K$, Higher-power views of the left RN regions corresponding to $A, D, G$, and $J . C, F, I, L$, Higher-power views of the right RN regions corresponding to $A, D$, $G$, and $J$. In normal animals both RNs are equally labeled $(A-C)$. In Gelfoam recipients virtually no RN neurons are labeled by FG on the left $(D, E)$, whereas labeling on the right is normal $(D, F)$. In Fb transplant recipients, very few $\mathrm{RN}$ neurons are labeled in the left $\mathrm{RN}(G, H)$, whereas the right $\mathrm{RN}$ is normally labeled $(G, I)$. In recipients of $\mathrm{Fb} / \mathrm{BDNF}$ transplants, numerous RN neurons are labeled in the left $\mathrm{RN}(J, K)$, and labeling is normal in the right $\mathrm{RN}(J, L)$. Scale bars, $100 \mu \mathrm{m}$. The scale bar in $J$ applies to $A, D, G$, and $J$; the scale bar in $K$ applies to $B, C, E, F, H, I, K$, and $L$.

Nakahara et al., 1996). We found that 30-40 RN neurons were FG labeled in animals receiving unmodified fibroblast transplants, which was considerably larger although not different statistically than the $\sim 10$ labeled cells in Gelfoam recipients. Similar numbers of RN neurons regenerated into peripheral nerve grafts placed into a comparable lesion (Richardson et al., 1984; Kobayashi et al., 1997). Unmodified fibroblast grafts may therefore offer the RST a growth-permissive environment similar to that provided by a peripheral nerve graft.

The most important feature, however, was the local delivery of $\mathrm{BDNF}$. Fb/BDNF transplants were homogeneously and robustly stained by X-gal histochemistry at 1 week, and many cells remained X-gal positive for at least 2 months, suggesting that the engineered cell transplants acted as an abundant and sustained source of BDNF that promoted the survival of RN neurons and regeneration of RST axons. This suggestion is supported by our findings that at least $7 \%$ of RN neurons regenerated caudal to the transplant in animals receiving $\mathrm{Fb} / \mathrm{BDNF}$ transplants, in contrast to $1 \%$ in $\mathrm{Fb}$ recipients, and that these transplants induced prof use raphe-spinal and dorsal root axon ingrowth, whereas growth into $\mathrm{Fb}$ grafts was sparse. Previous reports have demonstrated the effectiveness of BDNF in promoting RST regeneration. For ex- ample, as many as 200 neurons regenerated into a peripheral nerve graft when BDNF was administered adjacent to RN perikarya (Kobayashi et al., 1997), and RN neurons failed to regenerate into Schwann cell grafts unless BDNF was administered or the Schwann cells were engineered to express BDNF (Xu et al., 1995a; Menei et al., 1998). Exogenous BDNF also dramatically increased the number of chronically injured RN neurons that regenerated into a peripheral nerve graft (Ye and Houle, 1997). The enhanced regenerative response of RN neurons was likely mediated through trkB, the high-affinity receptor for BDNF, which is expressed by these neurons (Kobayashi et al., 1997).

\section{Mechanisms of RST regeneration in spinal cord}

Stimulated by BDNF, the axotomized RN neurons grew directly through the $\mathrm{Fb} / \mathrm{BDNF}$ transplants and caudally for up to 40-50 $\mathrm{mm}$ through host white matter. This pattern of growth differs from that of axotomized CST neurons, which responded to grafts of fibroblasts genetically modified to express NT-3 by growing through host gray matter both around the transplants and caudally for up to $9 \mathrm{~mm}$ (Grill et al., 1997). The differing patterns of growth shown by these two supraspinal systems suggest intrinsic 


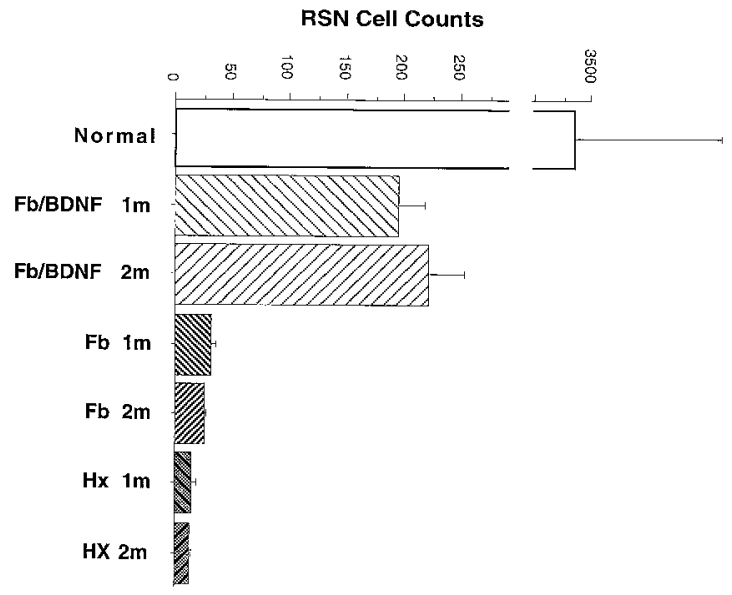

Figure 13. Bar graph comparing numbers of FG-labeled RN neurons among animal groups. The FG-labeled RN neurons in normal animals and animals that had received $\mathrm{Fb} / \mathrm{BDNF}, \mathrm{Fb}$, or Gelfoam transplants were counted and compared by one-way ANOVA, followed by Fisher's post hoc test 1 or 2 months after transplantation. Significantly more RN neurons $(\sim 7 \%)$ were labeled contralateral to surgery in animals receiving $\mathrm{Fb} / \mathrm{BDNF}$ transplants than in those receiving $\mathrm{Fb}$ or Gelfoam $(<1 \%) \cdot p<$ $0.00001 ; n=3$ for normal; $n=5$ for $\mathrm{Fb} / \mathrm{BDNF} 1 \mathrm{~m}, \mathrm{Hx} 1 \mathrm{~m}$, and $\mathrm{Hx} 2 \mathrm{~m}$; $n=6$ for $\mathrm{Fb} / \mathrm{BDNF} 2 \mathrm{~m}, \mathrm{Fb} 1 \mathrm{~m}$, and $\mathrm{Fb} 2 \mathrm{~m}$

differences in the regenerative capacities of these neurons and is consistent with other evidence showing that RN neurons regenerate more robustly than CST neurons in several different environments (Richardson et al., 1984; Tetzlaff et al., 1994; Ye and Houle, 1997; Dyer et al., 1998). Observations made in other systems also demonstrate intrinsic differences in neuronal regenerative capacity. After injury of the larval lamprey spinal cord, for example, only some populations of reticulospinal neurons regenerate (Davis and McClellan, 1994; Jacobs et al., 1997). Similarly, the neurons in the reticular nucleus of the adult rat thalamus, but not the neurons in other thalamic nuclei, regenerate into peripheral nerve grafts (Morrow et al., 1993), and only the CGRPcontaining neurons of the adult rat DRG appear to regenerate into fetal spinal cord transplants (Itoh et al., 1996). It seems likely that the more vigorous regenerative response of $\mathrm{RN}$ neurons allowed them to grow directly through the grafts and host white matter, whereas CST neurons were able to grow only through the more permissive substrate provided by gray matter.

The limited CST growth observed caudal to genetically modified fibroblast grafts is within the possible range of diffusion of NT-3 and may result from a tropic effect (Grill et al., 1997). Although BDNF may also have exerted a tropic influence, the greater length of regeneration through white matter that we observed for RST axons requires additional explanations. We found that the regenerated axons occupied the general location of the RST in normal white matter and terminated in regions of cervical gray matter that are the normal targets of these axons. This observation is consistent with the notion that the regenerating axons responded to cues similar to those that operate during development. The regenerating axons appear to have been able to grow in response to BDNF and these or other cues despite the well known inhibitory influence of CNS myelin. However, the numerous in vivo studies of myelin-associated neurite growth inhibitors have primarily focused on CST axons (Savio and Schwab, 1990; Schnell and Schwab, 1990, 1993; Schnell et al., 1994; Bregman et al., 1995; Z'Graggen et al., 1998), and whether they exert similar effects on RST axons has not been examined. It
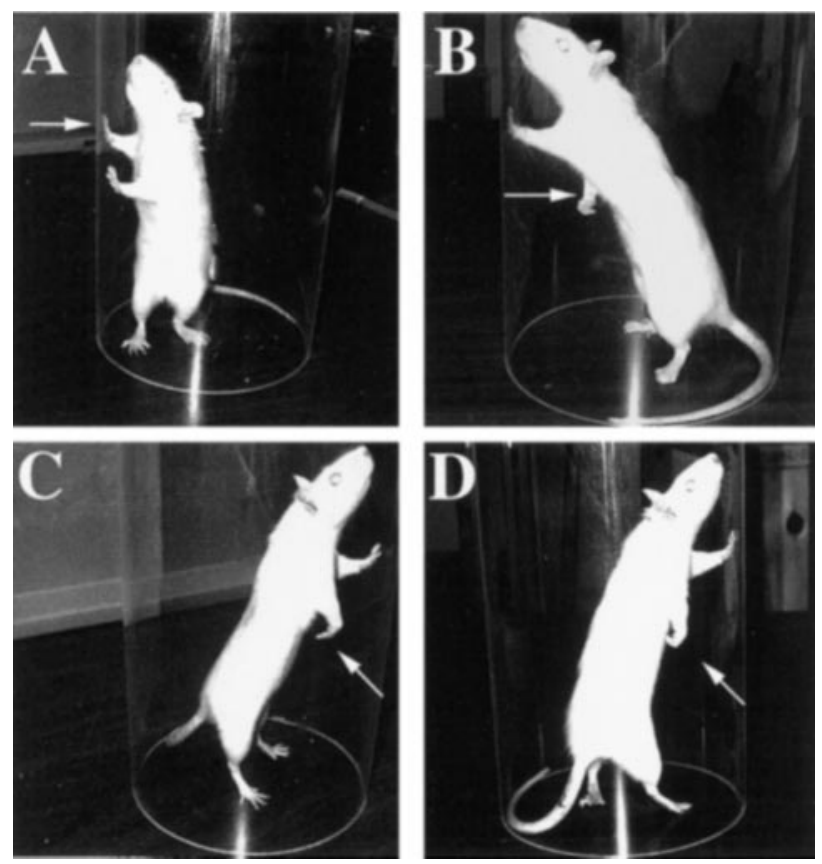

Figure 14. Photograph comparing forelimb use. Animals were analyzed in a cylinder test to study preferred forelimb use. $A, C$, Seven weeks after transplantation, $\mathrm{Fb} / \mathrm{BDNF}$ recipients used their forelimb ipsilateral to the lesion to explore the environment $(A)$, whereas $\mathrm{Fb}$ and Gelfoam recipients rarely did so $(C)$. The forepaw posture in animals with $\mathrm{Fb} / \mathrm{BDNF}$ transplants was nearly normal $(A)$, but $\mathrm{Fb}$ or Gelfoam recipients kept the forepaw ipsilateral to the lesion strongly flexed $(C) . B, D$, Seven weeks after the relesion at $\mathrm{C} 2$, animals with $\mathrm{Fb} / \mathrm{BDNF}$ transplants lost the normal forelimb posture and the ability to use the forelimb ipsilateral to the lesion $(B)$. In contrast, the relesion had little effect on forelimb posture and forelimb use in animals with $\mathrm{Fb}$ transplants $(D) . A, B$, Photographs of the same animal with an $\mathrm{Fb} / \mathrm{BDNF}$ graft taken before and after the relesion. $C, D$, From the same animal with an $\mathrm{Fb}$ graft before and after the relesion. Arrows in $A-D$ point to the forelimb ipsilateral to the lesion.

is possible, therefore, that RST axons are less susceptible to inhibition by myelin or, as suggested for other developing and adult axons whose axons grow through adult white matter (Wictorin et al., 1990a,b, 1992; Wictorin and Bjoklund, 1992; Davies et al., 1993, 1994, 1997; Li and Raisman, 1993; Oudega and Hagg, 1996; Li et a., 1997, 1998), that regenerating RST axons lack or downregulate the relevant receptors. The RST regeneration that we observed shares several characteristics with the growth through white matter reported for these other axons, including rapid growth rate (up to 1-2 mm/d) (Davies et al., 1994), growth of at least several centimeters (Wictorin et al., 1992), and the ability to find targets (Wictorin et al., 1990a, 1992; Davies et al., 1994, 1997). We speculate that in response to BDNF and the favorable substrate provided by the transplants, the intrinsically robust regenerative capacity of RN neurons allowed their axons to grow past the lesion site and through host white matter in response to cues that remained after injury and were relatively unaffected by the inhibitory influence of CNS myelin. Future experiments will determine whether additional systems of supraspinal axons are similarly responsive to neurotrophic factors supplied by transplants.

Recovery of function correlates with RST regeneration

Our behavioral results are consistent with the idea that regenerated RST axons contributed to recovery of forelimb motor func- 


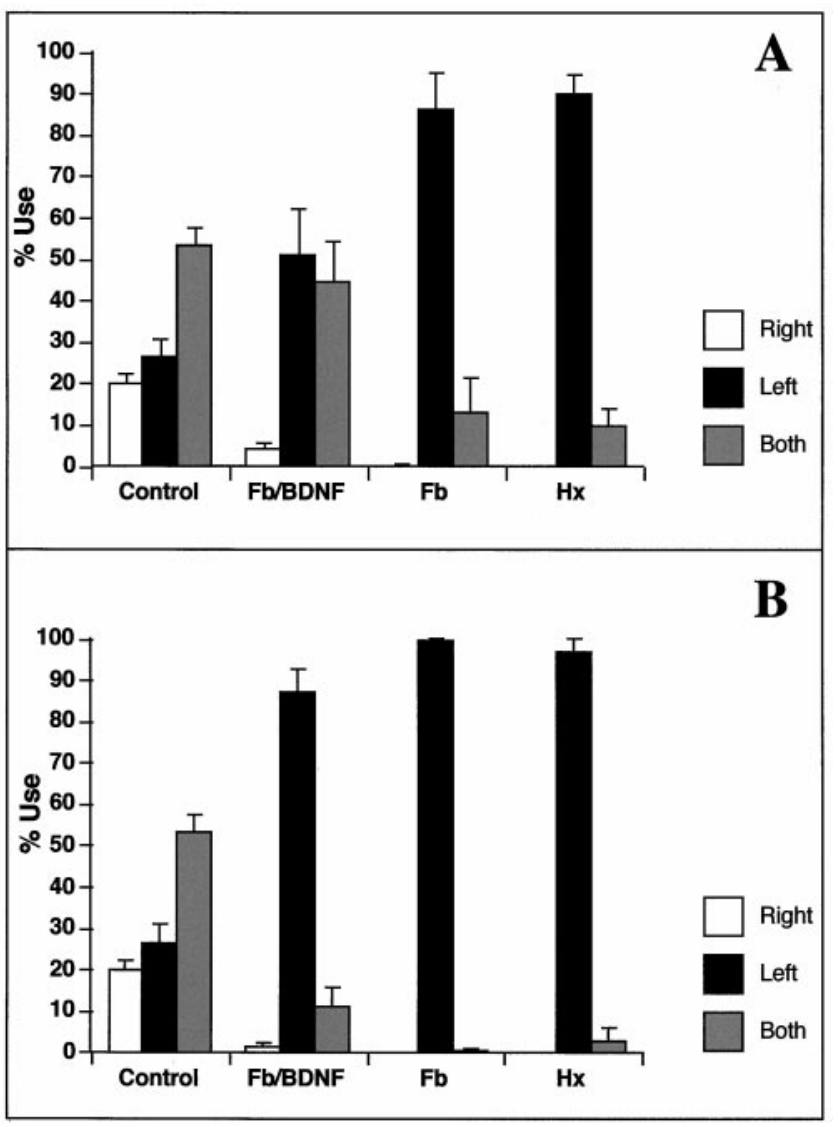

Figure 15. Behavioral analysis of forelimb use. Three weeks after transplantation, $\mathrm{Fb} / \mathrm{BDNF}$ recipients showed significant recovery of use of the injured limb alone or together with the uninjured limb, whereas $\mathrm{Fb}$ or Gelfoam recipients showed negligible use of the injured limb alone $(A)$. The relesion abolished most of the forelimb use in $\mathrm{Fb} / \mathrm{BDNF}$ recipients but had little effect on the $\mathrm{Fb}$ or Gelfoam recipients $(B) . n=6$ for $\mathrm{Fb} / \mathrm{BDNF}$ and $\mathrm{Fb}, n=5$ for $\mathrm{Hx}$.

tion. Animals receiving $\mathrm{Fb} / \mathrm{BDNF}$ transplants showed significant improvements in usage of the forelimb ipsilateral to the lesion. In contrast, those receiving unmodified fibroblasts or Gelfoam alone relied almost entirely $(\sim 90 \%)$ on the contralateral limb and failed to recover independent use of the impaired forelimb (Fig. $15 A$ ). Similar deficits have been reported after severe unilateral damage to the forelimb region of the sensorimotor cortex or basal ganglia. In these studies, independent use of the impaired forelimb for wall support and weight shifting along vertical surfaces did not recover substantially over a 6 month period (Kozlowski et al., 1996; Schallert and Kozlowski, 1998). Moreover, the functional recovery in $\mathrm{Fb} / \mathrm{BDNF}$ recipients followed a distinct progression during the first few weeks after surgery. At 1 week the rats did not use the forelimb ipsilateral to the lesion independently in this task, but by 3-4 weeks they used this limb alone $5-10 \%$ of the time and together with the contralateral limb $\sim 50 \%$ of time, similar to control rats. This progression of functional recovery correlates well with the anatomical recovery that we observed in the rubrospinal system. The RST axons regenerated at a rate of $1-1.5 \mathrm{~mm} / \mathrm{d}$ during the first month and sent branches with terminal bouton-like structures into the normal RST target region in cervical gray matter. This correlation suggests that the functional recovery in forelimb motor control can be attributed at least partially to the regeneration and reinnervation by RST axons. In addition, the animals showed no further functional recovery during the second month after surgery, and we observed no consistent difference in RST regeneration between animals that survived for 1 or 2 months. Additional mechanisms may contribute to the functional recovery in animals receiving $\mathrm{Fb}$ / BDNF transplants: (1) regeneration and sprouting by several descending pathways, including raphe-spinal and vestibulospinal axons that are known to respond to BDNF; (2) recovery of sensory function mediated by sprouting of dorsal roots; (3) preservation of segmental neuronal circuitry; and (4) facilitation of local segmental function by BDNF (Jakeman et al., 1998). However, the recovery does not appear to be attributable to the neuroprotective effect of BDNF on motor neurons because we found no qualitative difference in the cervical motor neuron pools in animals receiving transplants of $\mathrm{Fb} / \mathrm{BDNF}, \mathrm{Fb}$, or Gelfoam alone.

Our finding that a second lesion that cut RST axons rostral to the transplants apparently permanently abolished the recovered behavior in BDNF-transplant-treated animals suggests that RST regeneration is a major contributor to the recovery. However, we cannot rule out contributions from other descending pathways whose axons may also have regenerated or sprouted.

In summary, we have demonstrated that cellular delivery of BDNF by genetically engineered fibroblasts promoted longdistance regeneration of rubrospinal axons that at least partially mediate recovery of forelimb usage after cervical spinal cord injury.

\section{REFERENCES}

Bernstein-Goral H, Bregman BS (1993) Spinal cord transplants support the regeneration of axotomized neurons after spinal cord lesions at birth: a quantitative double-labeling study. Exp Neurol 123:118-132.

Bregman BS, Kunkel-Bagden E, Schnell L, Dai HN, Gao D, Schwab ME (1995) Recovery from spinal cord injury mediated by antibodies to neurite growth inhibitors. Nature 378:498-501.

Bregman, BS, McAtee M, Dai HN, Kuhn PL (1997) Neurotrophic factors increase axonal growth after spinal cord injury and transplantation in the adult rat. Exp Neurol 148:475-494.

Brosamle C, Schwab ME (1997) Cells of origin, course, and termination patterns of the ventral, uncrossed component of the mature rat corticospinal tract. J Comp Neurol 386:293-303.

Brown LT (1974) Rubrospinal projections in the rat. J Comp Neurol 154:169-187.

Caroni P, Schwab ME (1988) Antibody against myelin-associated inhibitor of neurite growth neutralizes nonpermissive substrate properties of CNS white matter. Neuron 1:85-96.

Chen A, Xu XM, Kleitman N, Bunge MB (1996) Methylprednisolone administration improves axonal regeneration into Schwann cell grafts in transected adult rat thoracic spinal cord. Exp Neurol 138:261-276.

Cheng H, Cao Y, Olson L (1996) Spinal cord repair in adult paraplegic rats: partial restoration of hind limb function. Science 273:510-513.

Choi-Lundberg DL, Lin Q, Schallert T, Crippens D, Davidson BL, Chang YN, Chiang YL, Qian J, Bardwaj L, Bohn MC (1998) Behavioral and cellular protection of rat dopaminergic neurons by an adenoviral vector encoding glial cell line-derived neurotrophic factor. Exp Neurol 154:261-275.

David S, Aguayo AJ (1981) Axonal elongation into peripheral nervous system "bridges" after central nervous system injury in adult rats. Science 214:931-933.

Davies SJ, Field PM, Raisman G (1993) Long fibre growth by axons of embryonic mouse hippocampal neurons microtransplanted into the adult rat fimbria. Eur J Neurosci 5:95-106.

Davies SJ, Field PM, Raisman G (1994) Long interfascicular axon growth from embryonic neurons transplanted into adult myelinated tracts. J Neurosci 14:1596-1612.

Davies SJ, Fitch MT, Memberg SP, Hall AK, Raisman G, Silver J (1997) Regeneration of adult axons in white matter tracts of the central nervous system. Nature 390:680-683.

Davis Jr GR, McClellan AD (1994) Long distance axonal regeneration of identified lamprey reticulospinal neurons. Exp Neurol 127:94-105. 
Diener PS, Bregman BS (1994) Neurotrophic factors prevent the death of CNS neurons after spinal cord lesions in newborn rats. NeuroReport 5:1913-1917.

Diener PS, Bregman BS (1998) Fetal spinal cord transplants support growth of supraspinal and segmental projections after cervical spinal cord hemisection in the neonatal rat. J Neurosci 18:779-793.

Dyer JK, Bourque JA, Steeves JD (1998) Regeneration of brainstemspinal axons after lesion and immunological disruption of myelin in adult rat. Exp Neurol 154:12-22.

Gage FH, Wolff JA, Rosenberg MB, Xu L, Yee JK, Shults C, Friedmann $\mathrm{T}$ (1987) Grafting genetically modified cells to the brain: possibilities for the future. Neuroscience 23:795-807.

Ghattas IR, Sanes JR, Majors JE (1991) The encephalomyocarditis virus internal ribosome entry site allows efficient coexpression of two genes from a recombinant provirus in cultured cells and in embryos. Mol Cell Biol 11:5848-5859.

Grill R, Murai K, Blesch A, Gage FH, Tuszynski MH (1997) Cellular delivery of neurotrophin-3 promotes corticospinal axonal growth and partial functional recovery after spinal cord injury. J Neurosci 17:5560-5572.

Himes BT, Goldberger ME, Tessler A (1994) Grafts of fetal central nervous system tissue rescue axotomized Clarke's nucleus neurons in adult and neonatal operates. J Comp Neurol 339:117-131.

Honmou O, Felts PA, Waxman SG, Kocsis JD (1996) Restoration of normal conduction properties in demyelinated spinal cord axons in the adult rat by transplantation of exogenous Schwann cells. J Neurosci 16:3199-3208

Horie H, Bando Y, Chi H, Takenaka T (1991) NGF enhances neurite regeneration from nerve-transected terminals of young adult and aged mouse dorsal root ganglia in vitro. Neurosci Lett 121:125-128.

Itoh Y, Waldeck RF, Tessler A, Pinter MJ (1996) Regenerated dorsal root fibers form functional synapses in embryonic spinal cord transplants. J Neurophysiol 76:1236-1245.

Iwashita Y, Kawaguchi S, Murata M (1994) Restoration of function by replacement of spinal cord segments in the rat. Nature 367:167-170.

Jacobs AJ, Swain GP, Snedeker JA, Pijak DS, Gladstone LJ, Selzer ME (1997) Recovery of neurofilament expression selectively in regenerating reticulospinal neurons. J Neurosci 17:5206-5220.

Jakeman LB, Wei P, Guan Z, Stokes BT (1998) Brain-derived neurotrophic factor stimulates hindlimb stepping and sprouting of cholinergic fibers after spinal cord injury. Exp Neurol 154:170-184.

Jang SK, Wimmer E (1990) Cap-independent translation of encephalomyocarditis virus RNA: structural elements of the internal ribosomal entry site and involvement of a cellular 57-kD RNA-binding protein. Genes Dev 4:1560-1572.

Jones, TA, Schallert T (1994) Use-dependent growth of pyramidal neurons after neocortical damage. J Neurosci 14:2140-2152.

Joosten EA (1997) Corticospinal tract regrowth. Prog Neurobiol $53: 1-25$.

Kawaja MD, Gage FH (1991) Reactive astrocytes are substrates for the growth of adult CNS axons in the presence of elevated levels of nerve growth factor. Neuron 7:1019-1030.

Kawaja MD, Rosenberg MB, Yoshida K, Gage FH (1992) Somatic gene transfer of nerve growth factor promotes the survival of axotomized septal neurons and the regeneration of their axons in adult rats. J Neurosci 12:2849-2864.

Kim DG, Kang HM, Jang SK, Shin HS (1992) Construction of a bifunctional mRNA in the mouse by using the internal ribosomal entry site of the encephalomyocarditis virus. Mol Cell Biol 12:3636-3643.

Kobayashi NR, Fan DP, Giehl KM, Bedard AM, Wiegand SJ, Tetzlaff W (1997) BDNF and NT-4/5 prevent atrophy of rat rubrospinal neurons after cervical axotomy, stimulate GAP-43 and T $\alpha 1$-tubulin mRNA expression, and promote axonal regeneration. J Neurosci 17:9583-9595.

Kozlowski DA, James DC, Schallert T (1996) Use-dependent exaggeration of neuronal injury following unilateral sensorimotor cortex lesions. J Neurosci 16:4776-4786.

Li Y, Raisman G (1993) Long axon growth from embryonic neurons transplanted into myelinated tracts of the adult rat spinal cord. Brain Res 629:115-127.

Li Y, Field PM, Raisman G (1997) Repair of adult rat corticospinal tract by transplants of olfactory ensheathing cells. Science 277:2000-2002.

Li Y, Field PM, Raisman G (1998) Regeneration of adult rat corticospinal axons induced by transplanted olfactory ensheathing cells. J Neurosci 18:10514-10524.

Liu Y, Himes BT, Moul J, Huang WL, Chow SY, Tessler A, Fischer I (1997a) Application of recombinant adenovirus for in vivo gene delivery to spinal cord. Brain Res 768:19-29.

Liu Y, Xia J, Ma DL, Faber DS, Fischer I (1997b) Tau-like proteins in the nervous system of goldfish. Neurochem Res 22:1511-1516.

Liu Y, Himes BT, Tryon B, Moul J, Chow SY, Jin H, Murray M, Tessler A, Fischer I (1998) Intraspinal grafting of fibroblasts genetically modified by recombinant adenoviruses. NeuroReport 9:1075-1079.

Mann R, Mulligan RC, Baltimore D (1983) Construction of a retrovirus packaging mutant and its use to produce helper-free defective retrovirus. Cell 33:153-159.

McDermott PE, Frydel B, Ullman MD, Schallert T, Emerich DF (1995) Implantation of encapsulated catecholamine and GDNF-producing cells in rats with unilateral dopamine depletions and Parkinsonian symptoms. Exp Neurol 132:62-76.

McTigue DM, Horner PJ, Stokes BT, Gage FH (1998) Neurotrophin-3 and brain-derived neurotrophic factor induce oligodendrocyte proliferation and myelination of regenerating axons in the contused adult rat spinal cord. J Neurosci 18:5354-5365.

Menei P, Monteromenei C, Whittemore SR, Bunge RP, Bunge MB (1998) Schwann cells genetically modified to secrete human BDNF promote enhanced axonal regrowth across transected adult rat spinal cord. Eur J Neurosci 10:607-621.

Miller AD (1990) Retrovirus packaging cells. Hum Gene Ther 1:5-14.

Miya D, Giszter S, Mori F, Adipudi V, Tessler A, Murray M (1997) Fetal transplants alter the development of function after spinal cord transection in newborn rats. J Neurosci 17:4856-4872.

Morgan RA, Couture L, Elroy-Stein O, Ragheb J, Moss B, Anderson WF (1992) Retroviral vectors containing putative internal ribosome entry sites: development of a polycistronic gene transfer system and applications to human gene therapy. Nucleic Acids Res 20:1293-1299.

Mori F, Himes BT, Kowada M, Murray M, Tessler A (1997) Fetal spinal cord transplants rescue some axotomized rubrospinal neurons from retrograde cell death in adult rats. Exp Neurol 143:45-60.

Morrow DR, Campbell G, Lieberman AR, Anderson PN (1993) Differential regenerative growth of CNS axons into tibial and peroneal nerve grafts in the thalamus of adult rats. Exp Neurol 120:60-69.

Nakahara Y, Gage FH, Tuszynski MH (1996) Grafts of fibroblasts genetically modified to secrete NGF, BDNF, NT-3, or basic FGF elicit differential responses in the adult spinal cord. Cell Transplant 5:191-204.

Novikova L, Novikov L, Kellerth JO (1996) Brain-derived neurotrophic factor reduces necrotic zone and supports neuronal survival after spinal cord hemisection in adult rats. Neurosci Lett 220:203-206.

Oudega M, Hagg T (1996) Nerve growth factor promotes regeneration of sensory axons into adult rat spinal cord. Exp Neurol 140:218-229.

Prewitt CM, Niesman IR, Kane CJ, Houle JD (1997) Activated macrophage/microglial cells can promote the regeneration of sensory axons into the injured spinal cord. Exp Neurol 148:433-443.

Rabchevsky AG, Streit WJ (1997) Grafting of cultured microglial cells into the lesioned spinal cord of adult rats enhances neurite outgrowth. J Neurosci Res 47:34-48.

Richardson PM, McGuinness UM, Aguayo AJ (1982) Peripheral nerve autografts to the rat spinal cord: studies with axonal tracing methods. Brain Res 237:147-162.

Richardson PM, Issa VM, Aguayo AJ (1984) Regeneration of long spinal axons in the rat. J Neurocytol 13:165-182.

Rosenberg MB, Friedmann T, Robertson RC, Tuszynski M, Wolff JA, Breakefield XO, Gage FH (1988) Grafting genetically modified cells to the damaged brain: restorative effects of NGF expression. Science 242:1575-1578.

Savio T, Schwab ME (1990) Lesioned corticospinal tract axons regenerate in myelin-free rat spinal cord. Proc Natl Acad Sci USA $87: 4130-4133$

Schallert T, Jones TA (1993) "Exuberant" neuronal growth after brain damage in adult rats: the essential role of behavioral experience. J Neural Transplant Plast 4:193-198.

Schallert T, Kozlowski DA (1998) Brain damage and plasticity: userelated enhanced neural growth and overuse-related exaggeration of injury. In: Cerebrovascular disease (Ginsberg MD, Bogousslavsky J, eds), pp 611-619. New York: Blackwell Science.

Schallert T, Lindner MD (1990) Rescuing neurons from trans-synaptic degeneration after brain damage: helpful, harmful or neutral in recovery of function? Can J Psychol 44:276-292.

Schnell L, Schwab ME (1990) Axonal regeneration in the rat spinal cord produced by an antibody against myelin-associated neurite growth inhibitors. Nature 343:269-272. 
Schnell L, Schwab ME (1993) Sprouting and regeneration of lesioned corticospinal tract fibres in the adult rat spinal cord. Eur J Neurosci 5:1156-1171.

Schnell L, Schneider R, Kolbeck R, Barde YA, Schwab ME (1994) Neurotrophin-3 enhances sprouting of corticospinal tract during development and after adult spinal cord lesion. Nature 367:170-173.

Schwab ME, Bartholdi D (1996) Degeneration and regeneration of axons in the lesioned spinal cord. Physiol Rev 76:319-370.

Shibayama M, Hattori S, Himes BT, Murray M, Tessler A (1998) Neurotrophin-3 prevents death of axotomized Clarkes nucleus neurons in adult rat. J Comp Neurol 390:102-111.

Snyder EY, Senut MC (1997) The use of nonneuronal cells for gene delivery. Neurobiol Dis 4:69-102.

Stichel CC, Muller HW (1998) Experimental strategies to promote axonal regeneration after traumatic central nervous system injury. Prog Neurobiol 56:119-148.

Taoka Y, Okajima K (1998) Spinal cord injury in the rat. Prog Neurobiol 56:341-358.

Tessler A, Fischer I, Giszter S, Himes BT, Miya D, Mori F, Murray M (1997) Embryonic spinal cord transplants enhance locomotor performance in spinalized newborn rats. In: Advances in neurology, Vol 72, neuronal regeneration, reorganization and repair (Seil FJ, ed), pp 291-303. Philadelphia: Lippincott-Raven.

Tetzlaff W, Kobayashi NR, Giehl KM, Tsui BJ, Cassar SL, Bedard AM (1994) Response of rubrospinal and corticospinal neurons to injury and neurotrophins. Prog Brain Res 103:271-286.

Tracey DJ (1995) Ascending and descending pathways in the spinal cord. In: The rat nervous system, Ed 2 (Paxinos G, ed.), pp 67-80. San Diego: Academic.

Tuszynski MH, Peterson DA, Ray J, Baird A, Nakahara Y, Gage FH (1994) Fibroblasts genetically modified to produce nerve growth factor induce robust neuritic ingrowth after grafting to the spinal cord. Exp Neurol 126:1-14.

Waldron HA, Gwyn DG (1969) Descending nerve tracts in the spinal cord of the rat. I. Fibers from the midbrain. J Comp Neurol 137:143-153.

Whittemore SR, Snyder EY (1996) Physiological relevance and functional potential of central nervous system-derived cell lines. Mol Neurobiol 12:13-38.

Wictorin K, Bjorklund A (1992) Axon outgrowth from grafts of human embryonic spinal cord in the lesioned adult rat spinal cord. NeuroReport 3:1045-1048.

Wictorin K, Brundin P, Gustavii B, Lindvall O, Bjorklund A (1990a) Reformation of long axon pathways in adult rat central nervous system by human forebrain neuroblasts. Nature 347:556-558.

Wictorin K, Clarke DJ, Bolam JP, Brundin P, Gustavii B, Lindvall O, Bjorklund A (1990b) Extensive efferent projections of intra-striatally transplanted striatal neurons as revealed by a species-specific neurofilament marker and anterograde axonal tracing. Prog Brain Res 82:391-399.

Wictorin K, Brundin P, Sauer H, Lindvall O, Bjorklund A (1992) Long distance directed axonal growth from human dopaminergic mesencephalic neuroblasts implanted along the nigrostriatal pathway in 6-hydroxydopamine lesioned adult rats. J Comp Neurol 323:475-494.

Xu XM, Guenard V, Kleitman N, Aebischer P, Bunge MB (1995a) A combination of BDNF and NT-3 promotes supraspinal axonal regeneration into Schwann cell grafts in adult rat thoracic spinal cord. Exp Neurol 134:261-272.

Xu XM, Guenard V, Kleitman N, Bunge MB (1995b) Axonal regeneration into Schwann cell-seeded guidance channels grafted into transected adult rat spinal cord. J Comp Neurol 351:145-160.

Ye JH, Houle JD (1997) Treatment of the chronically injured spinal cord with neurotrophic factors can promote axonal regeneration from supraspinal neurons. Exp Neurol 143:70-81.

Z'Graggen WJ, Metz GAS, Kartje GL, Thallmair M, Schwab ME (1998) Functional recovery and enhanced corticofugal plasticity after unilateral pyramidal tract lesion and blockade of myelin-associated neurite growth inhibitors in adult rats. J Neurosci 18:4744-4757. 